\title{
A naval damage incident recoverability toolset: Assessing naval platform recoverability after a fire event
}

\author{
Anthony Woolley $^{\mathrm{a}, *}$, John Ewer ${ }^{\mathrm{b}}$, Peter Lawrence ${ }^{\mathrm{b}}$, Steven Deere ${ }^{\mathrm{b}}$, Anthony Travers ${ }^{\mathrm{a}}$, Tom Whitehouse ${ }^{\mathrm{a}, 1}$, \\ Edwin Richard Galea ${ }^{b, * *}$ \\ ${ }^{a}$ Defence Science \& Technology Group, 506 Lorimer Street, Fishermans Bend, Victoria, 3207, Australia \\ ${ }^{\mathrm{b}}$ Fire Safety Engineering Group, University of Greenwich, Old Royal Naval College, Queen Mary Building, 30 Park Row, Greenwich, SE10 9LS, United Kingdom
}

\section{A R T I C L E I N F O}

\section{Keywords}

Damage control

Naval survivability

Recoverability

Simulation

Fire

Crew movement

\begin{abstract}
A B S T R A C T
Naval platform survivability is a key enabler to ensure maritime warfighting capability. Therefore, assessment of naval platform recoverability, after a damage event, is critical to assure platform survivability in a warfighting environment. To support such an assessment, an innovative modelling and simulation capability, known as the Naval Damage Incident Recoverability Toolset (NavDIRecT) is being developed. NavDIRecT is being designed as a component-based, open architecture providing the necessary framework to allow analysts to integrate domain models of their choosing. NavDIRecT will facilitate analysis of warfighting and peacetime damage events using a variety of mathematical models, thereby avoiding the limitations of other survivability assessment techniques. Development of NavDIRecT is exemplified by integrating the human movement simulator, maritimeEXODUS, the fire simulation environment, SMARTFIRE, and a three-dimensional naval platform model. NavDIRecT will enable analysis of crew interaction with damage events, thereby allowing acquisition programs and mission planners to examine platform survivability with respect to mission capability requirements. The impetus for NavDIRecT development is for assessment of naval platform survivability and mission success; however, the tools and techniques are equally suitable for use in incident management, training, and analysis of merchant and commercial shipping in accordance with the Safety of Life at Sea (SOLAS).
\end{abstract}

\begin{tabular}{|c|c|c|c|}
\hline \multicolumn{2}{|c|}{ Nomenclature } & HMAS & Her Majesty's Australian Ship \\
\hline AFFF & Aqueous Film Forming Foam & IMO & International Maritime Organization \\
\hline AR & Augmented Reality & IRM & Integrated Recoverability Model \\
\hline $\mathrm{C} \& \mathrm{C}$ & Command and Control & ISSAC & Integrated Ship Survivability Assessment Capability \\
\hline CA & Command Aims & $\mathrm{M} \& S$ & Modelling and Simulation \\
\hline CFD & Computational Fluid Dynamics & MBSE & Model-Based Systems Engineering \\
\hline $\mathrm{CO} 2$ & Carbon Dioxide & MMS & Main Machinery Space \\
\hline COTS & Commercial-off-the-Shelf & $\mathrm{mEX}$ & maritimeEXODUS \\
\hline DC & Damage Control & NavDIRec & T Naval Damage Incident Recoverability Toolset \\
\hline DCC & DC Centre & OCCABA & Open Circuit Compressed Air Breathing Apparatus \\
\hline DCSB & DC Section Base & PoI & Points-of-Interest \\
\hline EU & European Union & RAN & Royal Australian Navy \\
\hline EVI & Evacuation Index & SSEP & Ship Survivability Enhancement Program \\
\hline GPU & Graphics Processing Unit & SME & Subject Matter Expert \\
\hline FSSIM & Fire and Smoke Simulator & SMF & SMARTFIRE \\
\hline HLA & High Level Architecture & SOLAS & Safety of Life at Sea \\
\hline
\end{tabular}

\footnotetext{
* Corresponding author.

** Corresponding author. University of Greenwich, United Kingdom.

E-mail addresses: anthony.woolley@dst.defence.gov.au (A. Woolley); E.R.Galea@gre.ac.uk (E.R. Galea)

1 Retired since completing the work documented herein.
} 
SOP Standard Operating Procedures

SQL Structured Query Language

$\mathrm{V} \& \mathrm{~V} \quad$ Verification and Validation

VR Virtual Reality

\section{Introduction}

The concept of survivability for a modern naval platform is a whole-of-platform consideration. Referred to as 'Integrated Survivability', it is the temporal accumulation of effects, and the consequences of those effects, across the susceptibility, vulnerability and recoverability domains (Brett et al., 2017). Platform systems and processes acting as survivability control measures within each of those domains safeguard the platform, the crew and mission success from the threat environment. Ability to assess naval platform Integrated Survivability can help to ensure that the platform survives, and recovers from, damage incidents to enable successful completion of mission requirements. Other benefits of Integrated Survivability assessment include: evaluating the consequences of changes to Standard Operating Procedures (SOPs); evaluating the consequences of changes to platform configuration for the fleet-in-being; the ability to perform capability trade-off analysis during platform acquisition; evaluation of future survivability technologies; and training utilising screen based, Virtual Reality (VR), and Augmented Reality (AR) simulation. Consequently, there is a need to establish an 'Integrated Ship Survivability Assessment Capability' (ISSAC) to assess the ability of naval platforms, and the onboard Damage Control (DC) organisation, to survive damage incidents in high threat environments.

Important considerations for naval platform survivability are the decision-making process and the ability of the crew to manage, contain and recover from the ongoing and evolving situation. This is known as platform recoverability. Previously, recoverability had been considered an operational aspect of a naval platform and, therefore, not relevant to survivability (Boulougouris and Papanikolaou, 2004, 2013); and survivability was only defined in terms of susceptibility and vulnerability (Ball and Calvano, 1994; Boulougouris and Papanikolaou, 2004, 2013). However, the view that recoverability is not part of platform survivability is not universally accepted and others consider it an important factor when assessing platform survivability (Sajdak and Karni, 2006; de Yong, 2008; Piperakis and Andrews, 2014; Liwang and Jonsson, 2015; Brett et al., 2017). Unfortunately, recoverability is difficult to quantify, with a need to understand: system functionality and the relationship with platform capability and mission requirements; the effects of fire and flood; and the effects of crew response and damage control operations. Therefore, development of a recoverability modelling and analysis capability becomes a priority requirement for the larger Integrated Survivability analysis capability. Subsequently, the proposed first phase in the creation of the ISSAC framework is the development of a Naval Damage Incident Recoverability Toolset (NavDI$\operatorname{Rec} T)$.

The primary design goal for NavDIRecT is to integrate software technology that will provide a Modelling and Simulation (M\&S) environment for the evaluation of naval platform recoverability, after the occurrence of a damage event. The primary analysis goal for NavDIRecT is to analyse and quantify platform recoverability control measures with respect to varying platform capability and configuration options, and various threat scenarios.

NavDIRecT is being developed as an open architecture (Sims, 2012) environment to enable the use of different recoverability simulation models. Importantly, no specific recoverability model or software toolset will be hard-wired into the architecture. Designing NavDIRecT as an open architecture will allow it to be shared with collaborative partners without compromising intellectual property or security sensitivities of specific M\&S tools. Each collaborative partner may integrate models of their choosing to enable comparative studies or to facilitate the provision of specific modelling and analysis capabilities.

Initially, NavDIRecT is designed to model fire events and the crew response to such events, which, in some instances, might be initiated by a blast model to simulate explosive detonation. As the toolset evolves, corporate models for system damage, flooding and toxic hazard events. It will also include the capability to model crew combating damage and recovering system functionality to restore mission capability. Eventually, the NavDIRecT architecture will evolve into the ISSAC framework incorporating the temporal accumulation of effects across the three survivability domains of susceptibility, vulnerability and recoverability.

\section{Naval Integrated Survivability}

The Integrated Survivability 'onion', Fig. 1, presents layers of defence afforded to naval platforms to counter a high threat environment. When defences are breached, platform survivability is likely to become degraded and the platform more susceptible to ongoing threats. Each layer of defence has a specific survivability role:

1. susceptibility - to reduce the likelihood of being detected, engaged and hit by external threats;

2. vulnerability - to resist damage; and

3. recoverability - DC, and recovery of platform capability to ensure crew and platform safety, and mission success.

Unfortunately, there is no capability to provide whole-of-platform Integrated Survivability temporal analysis. However, software models to analyse individual aspects of susceptibility, vulnerability and recoverability exist (Buckland, 2008; Kok, 2012); and commercial-off-the-shelf (COTS) software integrating elements of the Integrated Survivability domains are available (Schofield, 2009; T\&E, 2019; SURMA, 2019). For example, the Integrated Recoverability Model (IRM) (T\&E, 2019) considers platform system modelling, fire modelling and crew movement for recovery of system functionality; SURMA (SURMA, 2019) considers signature management, vulnerability and fire effects; and SURVIVE (Schofield, 2009), was originally designed for vulnerability modelling with ability to incorporate elements of susceptibility, and a consideration for incorporating crew movement (Turner et al., 2006). Furthermore, with the aforementioned COTS software, issues arise relating to the proprietary nature of the underlying algorithms; national security; a lack of flexibility to plug-and-play domain specific models; and/or licensing costs. Other models, utilising, for example, Subject Matter Expert (SME) opinion (Gamble et al., 2014), genetic algorithms (Boulougouris and Papanikolaou, 2004) and probability analysis (Liwang and Jonsson, 2015), also have drawbacks and/or limitations. In many instances, the models consider survivability as a static concept. That is, they provide a single measure of survivability. This raises the question 'what is survivability?' (Brett et al., 2017). Is it, for example, the mission, crew safety, an ability to perform a specific

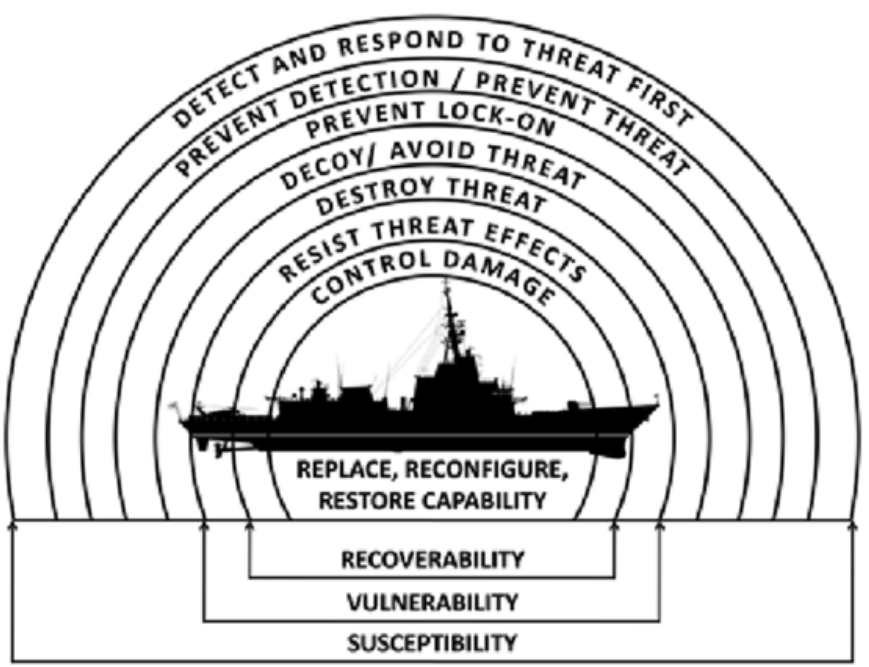

Fig. 1. The Integrated Survivability onion. 
function, or the ability to return to port? Furthermore, there is a need to assess the ongoing detrimental loss and/or incremental recovery of survivability, which, in turn, affects the ability of the platform to perform specific functions.

There is acceptance that the crew can perform operations to (hopefully) control the spread of damage and recover platform capability, but there is a lack of analysis regarding how this affects overall platform survivability. As such, the available models do not account for the interconnected nature of Integrated Survivability, nor do they consider temporal effects of ongoing/evolving damage or of recoverability operations. That is not to say the aforementioned models are invalid for their individual problem space; they are just not designed to account for the interactive nature of Integrated Survivability. Consequently, there is a need for a whole-of-scenario, whole-of-ship framework for Integrated Survivability analysis (Brett et al., 2017). Construction of this framework has commenced with the development of an integrated architecture to model the recoverability domain of Integrated Survivability, referred to as NavDI$\operatorname{RecT}$.

\section{Naval recoverability}

Naval platform recoverability forms the innermost rings of the Integrated Survivability 'onion', Fig. 1, whereby the crew and safety systems of the platform need to control the spread of damage and restore platform capability. Software tools that provide aspects of recoverability analysis do exist. For example, IRM (T\&E, 2019) combines human movement, fire modelling (using the Fire and Smoke Simulator (FSSIM) (Floyd et al., 2005)), flood modelling, and systems modelling to examine the effects of damage and the ability to restore system functionality. Other tools that may be used to provide elements of recoverability modelling include: maritimeEXODUS ( $m E X$ ) (Galea et al., 2013, 2016a) and Evacuation Index (EVI) (Azzi et al., 2011) to model pedestrian dynamics on board maritime platforms, primarily for evacuation analysis; SMARTFIRE (SMF) (Ewer et al., 2013; Wang et al., 2013), FSSIM (Floyd et al., 2005), and Fire Dynamics Simulator (McGrattan et al., 2016) to model fire and smoke progression through structures; and FREDYN (Ypma and Turner, 2019) for flood and stability modelling analysis. Tools such as the EXODUS suite (FSEG, 2019) of pedestrian and evacuation simulation software (including $m E X$ ), and the $S M F$ fire simulation software can also be coupled to explore the interaction of pedestrians with the developing fire environment to predict human survivability when exposed to fire incidents (Galea et al., 2016b, 2017). However, these tools are unable to provide whole-of-platform recoverability, or survivability, analysis.

At the onset of a naval platform damage event, one or more DC Centres (DCC) will be formed. Crew assigned to the DCC monitor the evolving situation, and control the allocation of resources and DC teams, in accordance with the aims and priorities of the platform's command team. DC team actions include identifying damage locations, locating and retrieving incapacitated crew, fighting fires, controlling damage, restoring system functionality, and decision-making to co-ordinate the DC response. Consequently, for a recoverability modelling capability to model the variety of damage events a platform and its crew are likely to encounter, a multi-disciplinary solution is required. This necessitates understanding, and analysis, of the scope and implications of all of the modelling requirements.

\section{Modelling requirements}

To elicit the M\&S requirements for an Integrated Survivability analysis capability, a Model-Based Systems Engineering (MBSE) (Robinson et al.,
2010) approach was implemented. This phase also included a review of Board of Inquiry reports (Ministry of Defence, 1982; Commonwealth of Australia, 1998; Drennan, 2008; Peniston, 2013), which provided understanding of actions that commonly occur during recoverability from naval damage incidents. In particular, a timeline for the fire incident on Her Majesty's Australian Ship (HMAS) Westralia in 1998 (Commonwealth of Australia, 1998) was created, Fig. 2, to enable identification of events and consequent actions that might occur during naval recoverability operations. Table 1 documents events noted in the Fig. 2 timeline.

To simulate the events that occurred aboard HMAS Westralia in 1998, as summarised in Table 1, would require M\&S capabilities to model:

- command hierarchy decision-making and management of DC operations;

- DC SOPs and crew movement; and

- the propagation of fire and smoke, cognisant of crew actions.

However, this is a simplistic, informal view, albeit one that gives insight into naval recoverability. Subsequently, formal requirements analysis commenced with a Work Domain Analysis (Liu and Woolley, 2015; Woolley and Gould, 2015), resulting in the identification of four categories of recoverability measures:

M1: Mission Effectiveness;

M2: Ship Survivability;

M3: Crew Safety; and

M4: Command Decision-making.

A sample of identified recoverability measures and associated metrics for each of the four categories is presented in Table 2. The majority of the metrics are static and provide insight regarding the success, or failure, of the recoverability process being analysed. However, metric M1.2 is proposed as a temporal metric measuring the progress of capability recovery. Where capability would be a measure of platform survivability or system functionality to perform a mission related task, depending on the analysis requirement. Analysis of the factors contributing to the metric will enable identification of changes to systems or processes that might improve the recoverability process, which could be implemented on the platform as configuration changes (such as, inclusion of fire insulation, moving the fixed location of fire mains) or as changes to recoverability and DC SOPs. Metric M1.2 will require definition of the survivability scenario and understanding of platform capability requirements with respect to the scenario, as discussed in Section 2 and in (Brett et al., 2017). Once the capability-survivability relationship is defined, and utilising the Fault Tree information from Metric 2.1, Metric M1.2 can be displayed temporally to show progress towards platform recoverability and survivability.

Analysis of the measures and metrics enabled identification of NavDIRecT M\&S functional requirements, including the ability to model:
- crew:
o decision-making;
o behaviour;
o fatigue;
o competency;
o movement through the platform; and
o incapacitation;

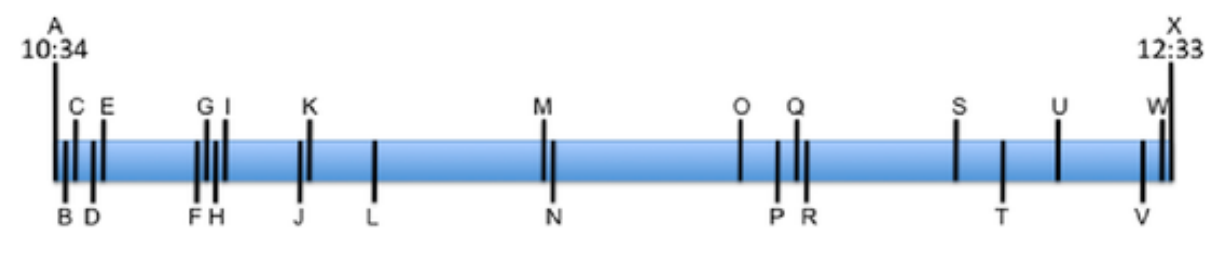


Table 1

Events during fire on HMAS Westralia.

\begin{tabular}{|c|c|c|}
\hline Key & Time & Event \\
\hline A & $10: 34$ & DCC formed when a substantial fuel leak was reported. \\
\hline B & $10: 35$ & $\begin{array}{l}\text { Fire reported in Main Machinery Space (MMS) on Starboard Main } \\
\text { Engine. }\end{array}$ \\
\hline $\mathrm{C}$ & $10: 36$ & $\begin{array}{l}\text { 1. MMS evacuation alarm activated. } \\
\text { 2. Bridge alarm activated; ship goes to emergency stations. } \\
\text { 3. Forward and aft DC Section Bases (DCSBs) formed. }\end{array}$ \\
\hline $\mathrm{D}$ & $10: 38$ & $\begin{array}{l}\text { 1. Personnel evacuated from Machinery Control Room. } \\
\text { 2. Isolation of affected systems. }\end{array}$ \\
\hline E & $10: 39$ & $\begin{array}{l}\text { SHIP BECOMES DISABLED } \\
\text { Command Priorities: (1) contain fire; and (2) identify casualties. }\end{array}$ \\
\hline $\mathrm{F}$ & $10: 49$ & $\begin{array}{l}\text { 1. DCC directs aft DCSB to establish MMS smoke boundaries and } \\
\text { boundary cooling. } \\
\text { 2. DCC directs Hose Team (HT) } 3 \text { be formed in forward DCSB. } \\
\text { 3. Two containment teams from aft DCSB to perform boundary } \\
\text { cooling. Standing Sea Fire Brigade to monitor bulkhead } \\
\text { temperatures. }\end{array}$ \\
\hline G & $10: 50$ & $\begin{array}{l}\text { Open Circuit Compressed Air Breathing Apparatus (OCCABA) } \\
\text { control board set up for HT } 1 \text {. HT } 1 \text { enters MMS. }\end{array}$ \\
\hline $\mathrm{H}$ & $10: 51$ & $\begin{array}{l}\text { HT } 1 \text { identifies hot spots using Thermal Imaging Camera and } \\
\text { decides firefighting technique to apply. }\end{array}$ \\
\hline I & $10: 52$ & HT 1 begins firefighting. \\
\hline $\mathrm{J}$ & 11:00 & $\begin{array}{l}\text { HT } 1 \text { ordered to exit MMS in preparation for Carbon Dioxide } \\
\text { (CO2) drench. }\end{array}$ \\
\hline K & 11:01 & $\mathrm{CO} 2$ drench remotely activated. \\
\hline $\mathrm{L}$ & $11: 08$ & Second $\mathrm{CO} 2$ drench occurs. \\
\hline M & $11: 26$ & $\begin{array}{l}\text { 1. DCC approves HT } 2 \text { to enter MMS. } \\
\text { 2. HT } 2 \text { identifies hot spots and decides firefighting technique to } \\
\text { apply. }\end{array}$ \\
\hline $\mathrm{N}$ & $11: 27$ & HT 2 commences firefighting. \\
\hline $\mathrm{O}$ & $11: 47$ & HT 2 exits MMS due to low air in OCCABA. \\
\hline $\mathrm{P}$ & $11: 51$ & HT 3 directed to enter MMS. \\
\hline Q & $11: 53$ & $\begin{array}{l}\text { 1. HT } 3 \text { identifies hot spots and decides firefighting technique to } \\
\text { apply. } \\
\text { 2. Aqueous Film Forming Foam (AFFF) dumped through ship } \\
\text { funnel into MMS. }\end{array}$ \\
\hline $\mathrm{R}$ & $11: 54$ & HT 3 continues firefighting. \\
\hline S & $12: 10$ & HT 1 enters MMS. \\
\hline $\mathrm{T}$ & $12: 15$ & HT 3 exits MMS. \\
\hline $\mathrm{Y}$ & $12: 21$ & HT 1 continues firefighting, targeting hot spots. \\
\hline V & $12: 30$ & HT 2 re-enters MMS. \\
\hline $\mathrm{W}$ & $12: 32$ & $\begin{array}{l}\text { 1. HT } 1 \text { advises HT } 2 \text { fire is extinguished. } \\
\text { 2. DCC advised fire extinguished. }\end{array}$ \\
\hline $\mathrm{X}$ & $12: 33$ & HTs rotated until smoke declared clear. \\
\hline
\end{tabular}

- DC techniques:

o firefighting;

o flood control; and

o toxic hazard response;

- safety systems; and

- system functionality mapped to platform capability and mission requirements.

The M\&S functional requirements are complemented by NavDIRecT system requirements, as discussed in the following sections, and include:

- the ability to utilise software tools and models akin to a 'plug-and-play' capability, which are often of different fidelity (Section 4.1);

- re-use of legacy software tools (Section 4.2);

- temporal management (Section 4.3);

- simulation speed (Section 4.4);

- repeatable simulations (Section 4.5);

- simulation replay (Section 4.6); and

- visualisation of simulations, and analysis of the outputs (Section 4.7).
Table 2

Sample of recoverability measures and metrics.

\begin{tabular}{|c|c|c|}
\hline Measure & Description & Metric \\
\hline \multicolumn{3}{|c|}{ M1: Mission Effectiveness } \\
\hline M1.1 & $\begin{array}{l}\text { Can the platform achieve Command Aims } \\
\text { (CAs)? }\end{array}$ & YES/NO \\
\hline M1.2 & $\begin{array}{l}\text { What is the degraded level of capability in } \\
\text { relation to CAs? }\end{array}$ & $\begin{array}{l}\text { Temporal percentage } \\
\text { change in capability }\end{array}$ \\
\hline M1.3 & $\begin{array}{l}\text { Time to recover platform capability in } \\
\text { accordance with CAs and Priorities. }\end{array}$ & Time (hh:mm:ss) \\
\hline \multicolumn{3}{|c|}{ M2: Ship Survivability } \\
\hline M2.1 & $\begin{array}{l}\text { Damage assessment immediately after } \\
\text { event. }\end{array}$ & $\begin{array}{l}\text { Fault Tree (Kabir, } \\
\text { 2017) }\end{array}$ \\
\hline M2.2 & Can the platform float? & YES/NO \\
\hline M2.3 & Can the platform move? & YES/NO \\
\hline M2.4 & Time to contain fire. & Time (hh:mm:ss) \\
\hline M2.5 & Time to contain flooding. & Time (hh:mm:ss) \\
\hline M2.6 & $\begin{array}{l}\text { Elapsed time for crew response to } \\
\text { commence. }\end{array}$ & Time (hh:mm:ss) \\
\hline \multicolumn{3}{|c|}{ M3: Crew Safety } \\
\hline M3.1 & $\begin{array}{l}\text { Crew casualties immediately after damage } \\
\text { event. }\end{array}$ & Integer \\
\hline M3.2 & $\begin{array}{l}\text { Crew incapacitation due to the ongoing } \\
\text { situation. }\end{array}$ & Integer \\
\hline M3.3 & $\begin{array}{l}\text { Time to evacuate crew from incident } \\
\text { scene. }\end{array}$ & Time (hh:mm:ss) \\
\hline M3.4 & Time to evacuate platform (if ordered). & Time (hh:mm:ss) \\
\hline
\end{tabular}

The NavDIRecT functional and system requirements are not currently afforded by any COTS recoverability modelling software (as discussed in Section 2); rather, the requirements will be achieved by the interconnection of various software models that provide elements of the recoverability modelling capability, connected in a temporal M\&S environment. Consequently, the NavDIRecT architecture must be capable of utilising legacy, bespoke and COTS M\&S software as required. The architecture must also be capable of utilising software capable of supporting the specific analysis requirements that have been identified for the system. For example, utilising software models of different fidelity. To enable the plug-and-play capability, interfaces specific to each software tool must be created to enable it to connect to the NavDIRecT architecture.

\subsubsection{Model fidelity}

The NavDIRecT environment will integrate various legacy, bespoke and COTS M\&S software, each of differing levels of fidelity. Fidelity, as defined by Burnett (Burnett, 2008, p.2), is the 'level of faithfulness of the reproduction, in accuracy and resolution, for both, form and function as measured in comparison to the entity or environment being simulated'. The United States Department of Defense defines fidelity as 'the degree to which a model or simulation represents the state and behaviour of a real world object or the perception of a real world object, feature, condition, or chosen standard in a measurable or perceivable manner; a measure of the realism of a model or simulation' (Department of Defense, 2016). The differing levels of fidelity between the software tools will pose a challenge during analysis and will constrain the accuracy of measurement in predicting outcomes. Use of low fidelity software tools may also result in a failure to predict crucial phenomena or behaviour. For example, when modelling fire, a zone model will not differentiate localised heating of a specific element within a complex three-dimensional space. Conversely, fire modelling using Computational Fluid Dynamics (CFD) has that capability. With respect to modelling human behaviour, using a course-node evacuation model for the crew of a naval platform, or a merchant ship, will not have the ability to explicitly model the interaction between individual crew. 
There is also the issue of data fidelity - the accuracy and resolution of the available data. During the phases of a naval platform's life cycle, from design through to disposal, the quality and quantity of available data, utilised to describe the platform and its systems, will vary. During early design phases, there is likely to be a low quantity of data available regarding layout, construction materials, system configuration, crew complement, and recoverability procedures. That is, the data is of 'low' fidelity. During later design phases, and during operational service, the quantity of the available data becomes much higher and, generally, is of better quality (having greater accuracy and relevancy). That is, the data is of 'high' (or higher) fidelity. In order to facilitate analysis using both low and high fidelity data requires the use of suitable software tools and models with the ability to support analysis of the available data.

There may also be a need to perform a rapid assessment of a design or technology to test its suitability for use in platform survivability. This may only require an approximation of the real-world system, needing less complex and less exact models. Alternatively, there may be need for a more detailed analysis to understand, for example, structural loading and/or stability in flooding conditions. This may require models of greater complexity, requiring higher resolution data, to more faithfully represent the real-world system. The plug-and-play requirement for NavDIRecT to facilitate software tools, models and data of different fidelity enables the analyst to use those tools that are best suited to specific analysis requirements.

\subsection{Legacy software}

NavDIRecT will include the use of bespoke legacy software tools that were designed to solve domain specific problems. The plug-and-play capability means that NavDIRecT will provide a framework to enable the repurposing of legacy software tools to facilitate recoverability analysis. Noting, it is not the goal of NavDIRecT development to create new software tools for individual elements of recoverability modelling and analysis. That remains the purview of the specialists utilising the legacy software. NavDIRecT will be a framework for whole-of-ship analysis using those tools.

\subsection{Temporal management}

The issue of temporal management is of concern due to repurposing the use of the legacy and COTS software. Legacy and COTS software, if they are continuous simulations (Birta and Arbez, 2007), will have specific methods of internal time management that do not necessarily match that of any other software being used. Alternatively, some software models may be discrete event simulations (Birta and Arbez, 2007), to model the sequence of events that occur during a scenario. Furthermore, each software model may have different initiation times, according to when they are required during the simulation. Finally, modelling may be required prior to commencing a simulation to identify the initial state of, and starting conditions for, the environment being modelled. Therefore, the different time steps, event times and initial modelling state will need to be unified. NavDIRecT will provide the underlying architecture to facilitate temporal connectivity between available legacy and COTS software, while also allowing for the inclusion of future COTS and bespoke M\&S software tools that may have a different understanding of time.

The temporal connectivity capability of the NavDIRecT architecture will keep the software synchronised while performing whole-of-ship recoverability M\&S. This will require the definition of a communication protocol to enable information passing and time synchronisation between each of the M\&S software tools.

\subsection{Simulation speed}

Speed of computation and, therefore, simulation speed is a consideration dependent on the usage applications for NavDIRecT. In the case of analysis and assessment for acquisition programs and in-service platform upgrades the importance of simulation speed is not a key driver so long as it does not impede delivery of the acquisition or upgrades. In the case of using NavDIRecT in a training environment, real time simulation will be a requirement to allow trainees to realistically interact with the environment. Finally, if NavDIRecT were to be deployed onboard naval (and merchant shipping) as an aid in the recoverability and DC process, faster than real time simulation will be required to scope out multiple optional resolutions and mitigations strategies.

The current modelling technology is suitable for the use in recoverability analysis for platform acquisition and in-service upgrade where real-time and faster than real-time simulation is not required. Real-time simulation is achievable at the cost of modelling fidelity (especially in the fire modelling domain), which can be an adequate compromise for training purposes. However, for a deployed recoverability support tool, requiring faster than real-time simulation, the current technology is unable to provide a viable solution.

\subsection{Repeatable simulations}

As with any experiment, recoverability simulations need to be repeatable to test the conditions of the simulation scenario, and establish standard deviations for the results.

\subsection{Simulation replay}

The requirement for simulation replay allows any simulation to be reviewed and analysed to understand the interaction of critical and non-critical events and the resultant evolution of the simulation.

\subsection{Visualisation of simulations}

The ability to visualise simulations using a variety of different modes (for example, DC and search teams) will enhance communication of results to stakeholders, and will also facilitate understanding of the results. Longer-term development will facilitate immersive simulation, with a human-in-the-loop for analysing scenarios, and for training DC practitioners.

\section{NavDIRecT framework}

Ongoing analysis of the M\&S requirements has identified a possible NavDIRecT framework solution. The proposed architecture, Fig. 3, consists of four key components: (1) Simulation Engine; (2) Physical Phenomena Models; (3) Damage Command \& Control (C\&C) Module; and (4) Databases. Arrows in Fig. 3 show connectivity between the components. Due to its complexity, NavDIRecT is being developed over a number of phases. The current phase of development has communication occurring between 'Fire \& Smoke Simulation' and 'Crew Movement' to simulate crew interaction with the fire. Fire simulation occurs during runtime to afford realistic modelling of crew interaction with the fire, and the ability to model the effects of changes to DC SOPs, and DC safety systems.

\subsection{Simulation Engine}

The Simulation Engine will provide the 'back-bone' for NavDIRecT. Primarily, it will be required to manage the complexities of temporally aligning simulation models during runtime, and communicate information and instructions between the simulation models. To provide the required runtime functionality, implementing NavDIRecT utilising High Level Architecture (HLA) (Reid, 2000; Cramp, 2009) was initially considered. The advantages of HLA are the provision of in-built temporal management, and its flexibility with data management. Unfortunately, HLA is a complex simulation environment, requiring significant upfront resource expenditure to build, and maintain, a suitable simulation environment. HLA is best suited for large scale, multiparty, low-medium data environments for long-term M\&S solutions (Reid, 2000). Unfortunately, the (financial and personnel) resourcing constraints imposed on the development of NavDIRecT meant that HLA was not a feasible solution. An al- 


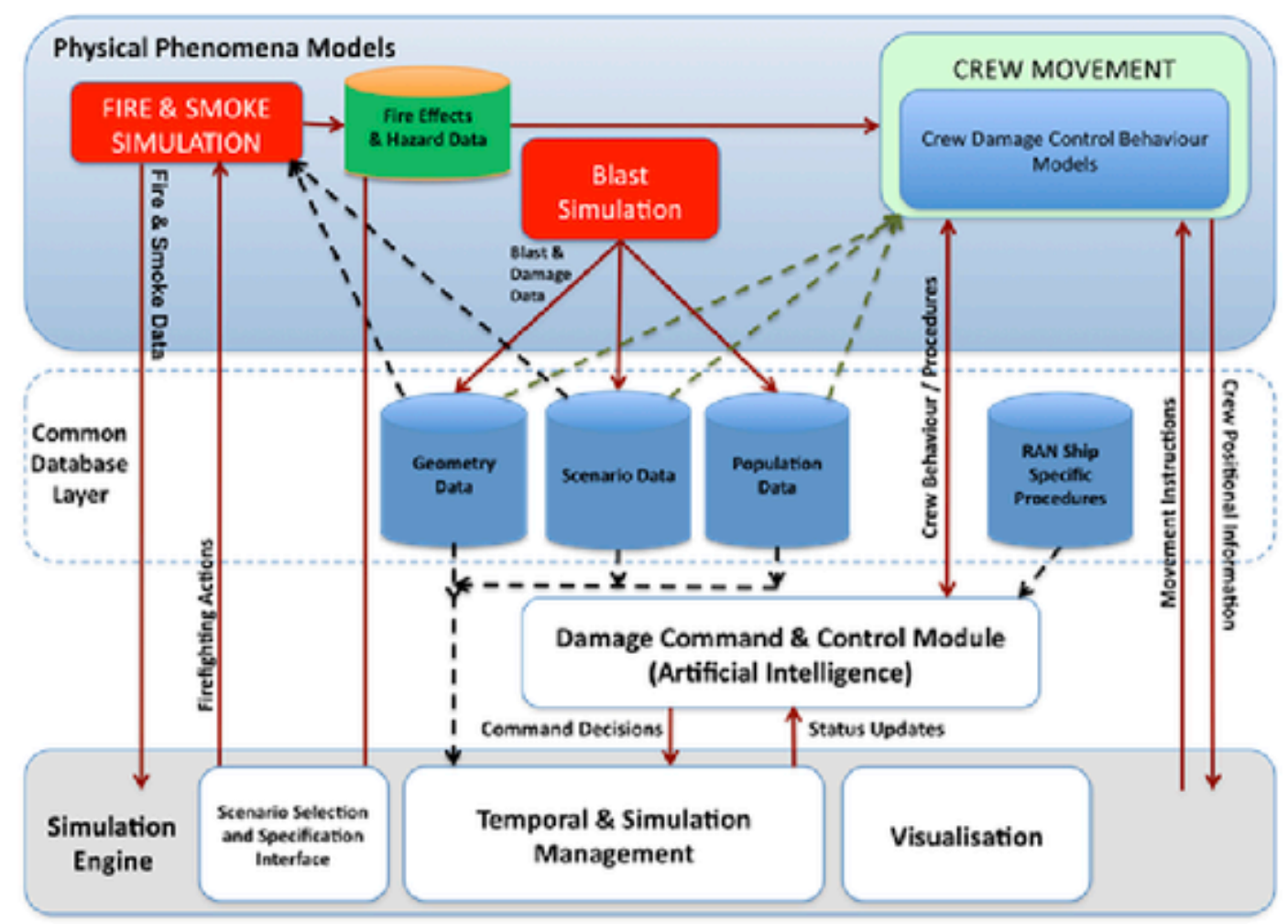

Fig. 3. NavDIRecT framework.

ternative to using HLA is a bespoke solution, utilising a 'game engine'. This has advantages in producing an easy to build M\&S architecture in line with the NavDIRecT requirement of integrating individual simulation tools within a common framework. The game engine provides capabilities for use in temporal and data management, thereby achieving the same functionality that would be provided by HLA. The main consideration regarding the use of a game engine is that, if not managed properly, this form of bespoke solution may result in a 'piecemeal' framework unable to provide suitable compatibility between simulation models.

The development of game engines has progressed due to significant investment within the computer game industry to create computer games that more readily take advantage of advances in computer hardware design and offer more realistic and immersive supporting models (Söbke and Streicher, 2016). The basic architecture of a game engine often has core functionality consisting of a physics module (for effects and movement), an artificial intelligence capability (for in-game characters not controlled by human players), and a rendering engine (for graphics) within a temporally connected environment (Söbke and Streicher, 2016; Vasudevamurt and Uskov, 2015). Also, the use of HLA is not precluded from this solution. As with other simulation tools that would be integrated into the NavDIRecT framework, HLA simulations may be adapted to suit (Söderbäck, 2017). Furthermore, if required and if resources became available, the bespoke game engine solution might be adapted to HLA.

The architecture provided by game engines, therefore, ideally suits the current NavDIRecT M\&S system requirements, without the overhead required for the implementation of HLA. In particular, with a growing third-party middle-ware library of software tools, Unity (Vasudevamurt and Uskov, 2015; Unity, 2019) was selected as providing a sufficiently comprehensive and cost-effective solution for the implementation of the Simulation Engine framework, Fig. 3, required by NavDI$\operatorname{RecT}$.

\subsection{Physical phenomena models}

The Physical Phenomena Models are those that simulate the physical behaviours of the required scenarios, emulating the real world environment. the current phase of NavDIRecT development, specific off-the-shelf and bespoke software are being utilised to model blast and fragmentation, fire, and crew movement and response. Future development will include examining the inclusion of other phenomena, such as flooding, toxic hazard, system repair and damage mitigation. The physical phenomena models to be included during the current phase of development are:

1. CVAM (Buckland, 2008) to model explosive blast and fragmentation events that will initiate recoverability scenarios within NavDIRecT. CVAM provides a capability to model platform structures and systems against a variety of above water, internal and external detonation effects. System damage and the resultant effects on platform capability are currently represented by Fault Trees. The CVAM model was partially validated by the Ship Survivability Enhancement Program (SSEP) utilising ex-HMAS Derwent (the SSEP experimental design is documented in (Howe, 1996); validation analysis is not available in the public domain);

2. maritimeEXODUS (mEX) (Galea et al., 2013, 2016a) to model crew movement. The $m E X$ evacuation model has an extensive validation history and ability to couple with CFD fire simulation (Galea et al 2004, 2013). It is used to perform the human factors simulations in NavDIRecT. mEX is designed for applications in the maritime industry, including ship design, compliance with International Maritime Organization (IMO) certification and naval ship code requirements, crew training, development of crew procedures, resolution of operational issues and accident investigation. The $m E X$ software takes into consideration various interactions: people-people; people-fire; and people-structure. It comprises five core interacting models: PASSENGER, MOVEMENT, BEHAVIOUR, TOXICITY and HAZARD. The PASSENGER model describes an individual as a collection of defining attributes and variables such as name, gender, age, maximum unhindered fast walking speed, maximum unhindered walking speed, response time and agility. The HAZARD model controls the atmospheric and physical environment by importing the predicted fire hazard data, like those generated by the SMF CFD fire model. The TOXICITY model determines the physiological effects on an individual exposed to the toxic and thermal environment dis- 
tributed by the HAZARD model. The $m E X$ software has a number of unique features, such as the capability to represent the performance of both naval personnel and civilians in the operation of watertight doors, vertical ladders, hatches and $60^{\circ}$ stairs. Another feature of the software is the ability to assign crew and passengers a list of itinerary tasks to perform. The itinerary tasks can represent a vast breadth of real world tasks from donning appropriate apparel to performing compartment searches. Many itinerary tasks were developed as part of the Engineering and Physical Sciences Research Council funded project, named EGO (Deere et al., 2008), which introduced several naval specific tasks into the software, such as 'blanket search' and the 'repeat' command to represent a crew member on patrol; and

3. SMF (Ewer et al., 2013; Wang et al., 2013) to model fire and smoke. $S M F$ is an advanced suite of inter-coupled tools allowing users to rapidly and reliably create, simulate, interrogate and analyse fire simulation problems. Highly intuitive and interactive components allow both expert and novice users to build/specify a fire simulation geometry, define a scenario, specify a suitable CFD mesh, simulate the effects of the fire and to visualise the results. The specification tools allow considerable flexibility to configure arbitrarily complex fire scenarios in the built environment. The SMF numerical engine is highly interactive, providing run-time visuals, numerical results and graphs. The software can simulate hot, turbulent, buoyant flows with convective, conductive and radiative heat transfer. Fires can be represented as volumetric heat sources, mass sources of a gaseous fuel (using an eddy dissipation combustion model) or as burnable surfaces that can ignite and spread flaming combustion. Parallel workstation, multi-core and Graphics Processing Unit (GPU) acceleration are being developed and hazard coupling to evacuation modelling is fully supported (Sauter, 2015).

Ongoing development of crew behaviour models, using cognitive analysis (Liu and Woolley, 2015; Woolley and Liu, 2016), will be implemented within $m E X$ to control artificial agents representing crew performing recoverability operations. Using cognitive analysis techniques will enable realistic representation of crew behaviour when performing activities, such as blanket search and firefighting. Furthermore, DC procedures can be platform specific, and there will be variation between platform classes and with merchant shipping. Therefore, cognitive analysis provides a method to identify behaviour relevant to the domain of interest. The advantage with implementing realistic crew behaviour models is the ability to analyse changes to SOPs and changes to platform configuration.

\subsection{Damage Command \& Control Module}

This bespoke module, yet to be implemented, represents decision-making within DCC and the naval platform's chain-of-command. To construct this module, knowledge elicitation cognitive analysis techniques will be utilised during interviews with experienced naval DC personnel (Liu and Woolley, 2015). The knowledge gained will form the basis of cognitive reasoning models for DC decision-making.

\subsection{Data storage - common database layer}

Several databases will service the NavDIRecT framework, to enable the recording of runtime data for future analysis and simulation replay, and to act as a repository for data required during runtime (such as, platform configuration). One proposed method of database implementation is to use a NoSQL distributed architecture (Burd, 2011). NoSQL allows for high availability, scalability and robustness of the backend systems and, as a result, they power many commercial enterprises that require a large online presence (for example, DynamoDB at Amazon Web Services (Amazon, 2019), and Cassandra used by eBay and Netflix (Cassandra, 2016).

Traditional Structured Query Language (SQL) underperforms when servicing hundreds of thousands of individual data requests. Conversely, NoSQL systems satisfy these demands (at the potential cost of compromising consistency; that is, compromising the rules governing database transactions) by allowing multiple computer servers to share the load across one seamless system. The advantage with this approach for a small-scale M\&S capability, like NavDIRecT, is that data can be quickly, robustly and reliably accessed, with the benefit of ease of scalability as the system evolves. For individual cases, where three or four simulation tools are connected for a simulation run, there is no significant benefit over traditional SQL systems but, when stochastic runs are considered, the value of a distributed NoSQL system becomes apparent. Many simulations can be run in parallel, and in batches, to reliably traverse a large solution space for the analysis of a number of M\&S options and scenarios.

\section{System usage}

It is envisaged that NavDIRecT will have six modes of operation, with data being saved at intervals during simulation runs, as shown in Fig. 4.

\subsection{Set-up mode}

In this mode, the user constructs scenarios to be modelled. The user can, for example, define the initial location of the crew agents, and tasks they are to perform. The state of the platform may also be specified, for example angle of heel and trim, and initial state information such as whether watertight doors and hatches are open or closed. The user may also define the initiation of the fire scenario, whether it commences from a blast event, or as a result of ignition from other sources. Further, previously saved scenarios and simulations may be reloaded for simulation replay or modification.

\subsection{Simulation mode}

This mode makes use of the integrated fire and crew movement modelling to simulate teams performing fire DC operations. Some recoverability scenarios may not involve fire and may only involve crew movement and tasks. In the early phases of NavDIRecT development, no user interaction will occur during simulation.

\subsection{Interactive Mode}

When implemented, this mode will enable users to control the movement and behaviour of crew agents in real-time during a simulation. All interactions will be logged and analysed to enable, for example, the validation of new SOPs and command decisions. Interactive Mode is an additional mode of operation to be implemented during later phases of NavDIRecT development.

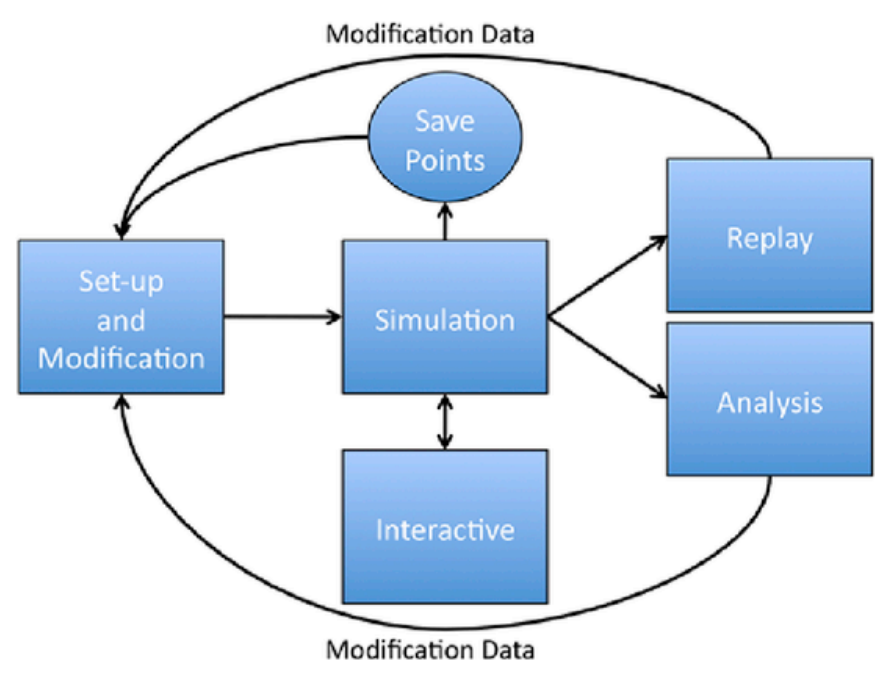

Fig. 4. NavDIRecT system usage. 


\subsection{Replay mode}

This mode provides functionality to replay previously modelled simulations. At any point during replay, the user may stop the simulation and identify changes to be implemented in follow-up scenarios. Changes to the scenario are implemented in the Modification Mode, which involves returning to the closest Save Point, implementing the required changes in Setup Mode, and re-starting the simulation from the Save Point.

\subsection{Analysis Mode}

Analysis Mode will allow the user access to the numerical and/or behavioural data produced by the simulations. Upon examination of the data, the user may decide to further modify a scenario. Changes to the scenario will be implemented in the Modification Mode.

\subsection{Modification Mode}

During Replay and Analysis Modes, the user may wish to modify the scenario at a key point in the simulation and continue the simulation from that point with modified conditions or actions. This is achieved in the Modification Mode, which allows the user to access the closest Save Point, implement changes to the model via the Setup Mode and restart the simulation in the Simulation Mode.

\subsection{Save Points}

During a simulation, simulation data will be continuously saved for analysis purposes, or for simulation replay. This will also enable users to re-start a simulation at any point within the simulation without the need to re-commence from the beginning.

\section{Simulating crew behaviour}

Crew behaviour and DCC decision-making is modelled within 'Crew Damage Control Behaviour Models' and the 'Damage Command \& Control Module' as depicted in Fig. 3. Behaviour responses relating to local conditions affecting crew agents will be implemented within the 'Crew Movement' model. High-level decision-making, such as prioritising recoverability operations, will be implemented within the 'Damage C\&C Module'. To assist with decision-making, and situation awareness within the simulation, three views of the simulated environment are defined: World View; Agent View; and DCC View. The 'Crew Movement' model will be aware of the crew agents' Physical State and the Action State being performed, with each state contributing to the three simulation views. Two other states necessary to perform recoverability related decision-making are also defined: External Decision State; and Internal Decision State.

\subsection{World View}

The World View represents the totality of the situation occurring within the simulation, untainted by crew agent perceptions of what might be occurring. The World View gives the user access to all simulation information defining the current state of the environment and the crew. This will include information that cannot be perceived by agents within the simulation.

\subsection{Agent View}

This represents the information available to individual crew agents. The Agent View is an abstraction of the World View based on what crew agents would realistically sense in their vicinity, equivalent to the perceptions of real platform crew. Since this view is based on agent perceptions, information collected by the agent may be incomplete, inaccurate and/or out-of-date. The
Agent View is to be implemented within 'Crew Damage Control Behaviour Models' (see Fig. 3).

\subsection{DCC view}

This represents the amalgamated information as received from crew agents for the simulated DCC to develop a situational awareness of the ongoing and evolving scenario. Since the DCC View is an amalgamation of information from a variety of sources, including the Agent View, the situational awareness developed by the DCC View may be incomplete, inaccurate and/or out-of-date. This situational awareness information will be utilised by the 'Damage Command \& Control Module' to define DC aims and priorities, and for resultant decision-making (see External Decision State).

\subsection{Action State}

An Action State simulates the activity crew agents are to perform. An Action State will include information concerning time taken for the agent to perform the activity, which is passed to Physical State to calculate factors such as crew fatigue, or remaining air in the Open Circuit Compressed Air Breathing Apparatus (OCCABA). Action State also contains information concerning the crew agent's observations of the environment. For example, a crew agent might observe 'water tight door closed'. This observation will be communicated to Internal Decision State to decide whether or not to open the door.

\subsection{Physical State}

This represents the physiological state of the agent (for example, level of fatigue), their physical skills, location, and equipment they might be carrying. The Physical State of crew agents will be affected by activities they are performing (as directed by the Action State). Longer-term consideration will need to be given to crew agents working in teams, and understanding how the combined skill of the team affects recoverability operations. Initially, though, Physical State will be limited to the current capabilities of $m E X$ ('Crew Movement' modelling capability) for agents to react to fire hazards. Longer-term development will include physiological state, physical skills, and the effects of equipment being carried.

\subsection{External Decision State}

External Decision State identifies recoverability priorities based on current situation awareness, and performs decision-making in response to those priorities. Consequently, DCC View provides input (based on simulated crew perceptions) to the External Decision State. Rules to perform decision-making will be identified using knowledge elicitation techniques (Liu and Woolley, 2015).

For example, during the fire on HMAS Westralia in 1998, the commanding officer was monitoring the state of the fire and, at 1100 (Point $\mathrm{K}$ in Fig. 1 and Table 1 ) decided it was necessary to control the fire with a $\mathrm{CO}_{2}$ drench. This was a critical decision, since a $\mathrm{CO}_{2}$ drench creates an unsafe environment for the crew and, at the time, the location of four crew members was unknown, possibly last seen in the Main Machinery Space (MMS). The commanding officer had to make the decision whether to risk the lives of four unaccounted for crew or risk the lives of the remaining crew and the safety of the platform. Another consideration for performing this action is that the $\mathrm{CO}_{2}$ drench precluded the crew from entering the MMS until $20 \mathrm{~min}$ had elapsed. After $20 \mathrm{~min}$, the MMS was then deemed safe to re-enter so crew could perform a search for incapacitated personnel or perform manual firefighting operations. Priority based decision-making will occur on an ongoing basis during an incident and, as the situation evolves, so will the priorities and the available information.

\subsection{Internal Decision state}

This represents the cognitive ability of crew agents and will re- 
decision-making for crew agents in relation to interaction with the local environment. Upon deciding actions for crew agents to perform, Internal Decision State communicates the action to the Action State. Knowledge elicitation techniques will be used to define crew behaviours, and to identify decisions required to enact that behaviour (Liu and Woolley, 2015; Woolley and Liu, 2016). The Internal Decision State is governed by priorities set by the External Decision State.

\section{Test case}

To test the capabilities of NavDIRecT during development, a scenario was developed using a simple, generic structure consisting of two rooms connected by a corridor, with a small population of agents. In this test case, an agent, identified as 'Warden' in the $m E X$ view of Fig. 5, is tasked to walk through the structure, systematically visiting each compartment and manually searching for the presence of fire. If no fire is detected, the Warden will move to the next compartment and repeat the search process. On detecting a fire, the Warden is tasked with closing the door to the fire compartment and warning other occupants about the fire thus instigating their evacuation. The Warden is provided with an itinerary to follow a set path walking through the structure, visiting each compartment and searching for fires (see the $m E X$ view of Fig. 5, labelled "Warden's search path"). Fig. 6 and Fig. 7 present screen captures of the coupled $m E X-S M F$ simulation (FSEG, 2018a). The $m E X$ simulation is the primary window in Figs. 6 and 7, with the SMF simulation window shown behind and below the $m E X$ simulation window. Actions occurring in the $m E X$ simulation that affect the fire are reflected in the $S M F$ simulation. In the $m E X$ window of Fig. 6, the warden is standing outside the closed door, and the fire is burning in the cabin to the right (shown in the SMF simulation window). In

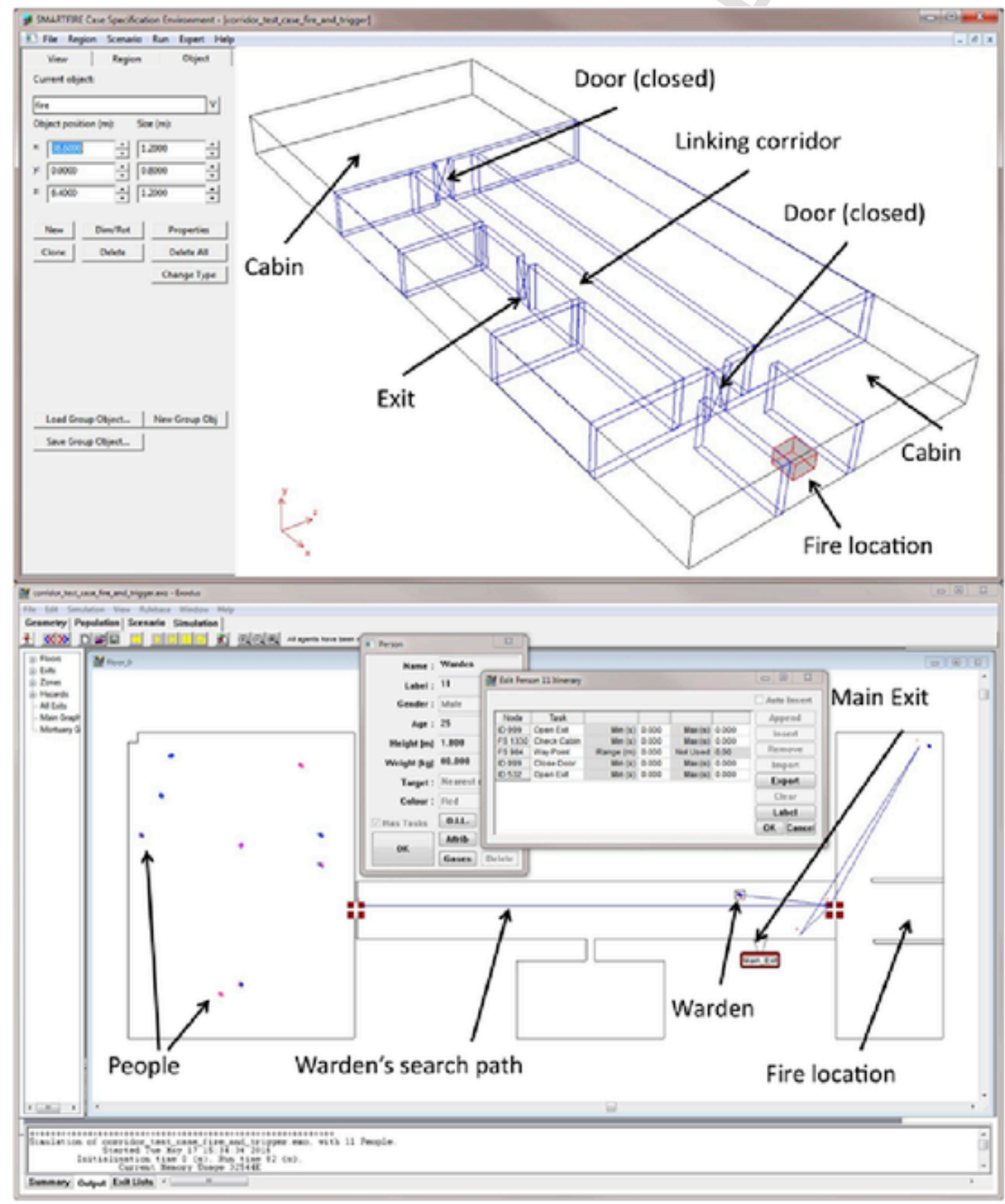

Fig. 5. SMF fire modelling (top) and mEX people movement (bottom) coupling. 


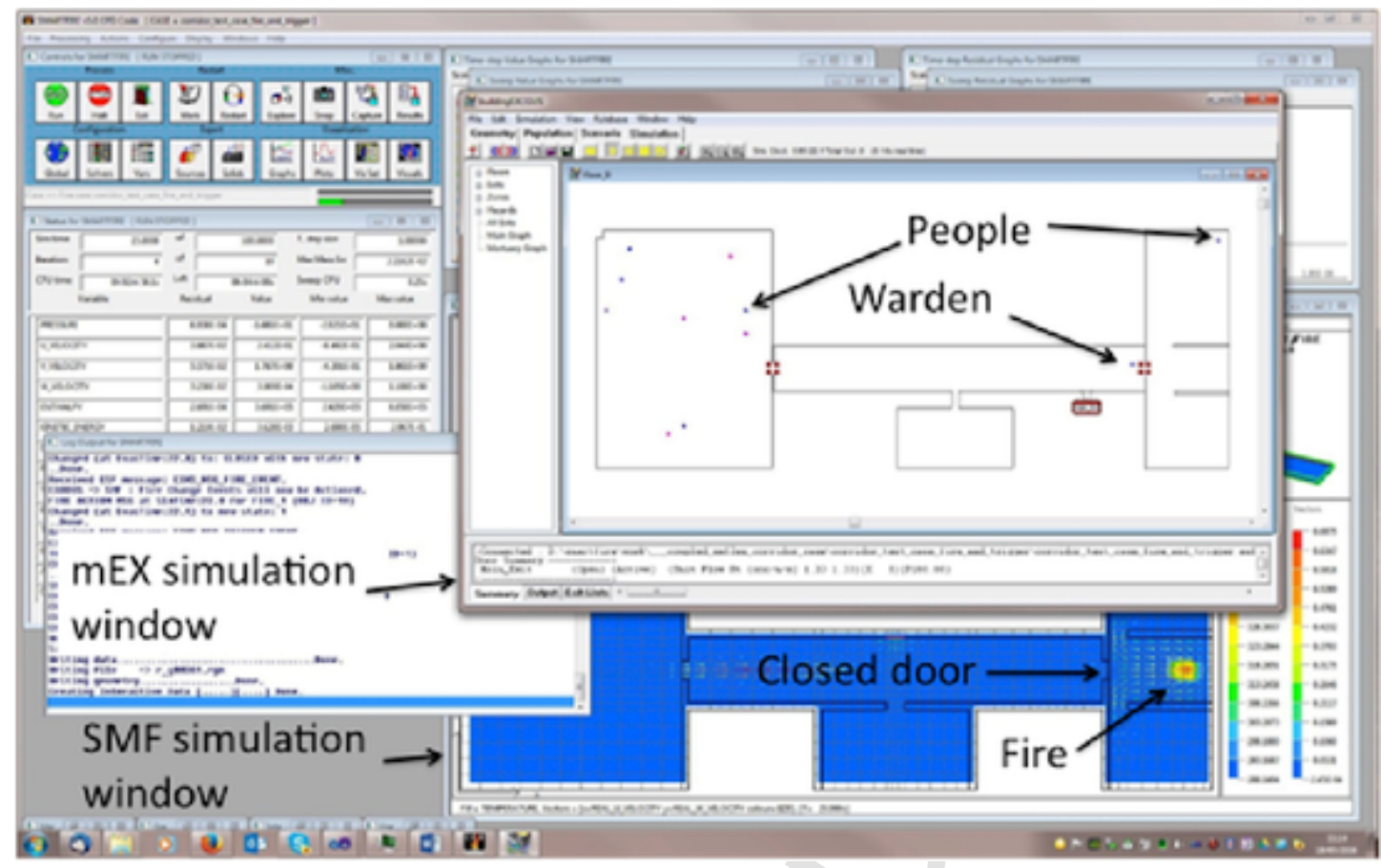

Fig. 6. SMF and mEX coupling, showing the spread of fire while the door to corridor is closed.

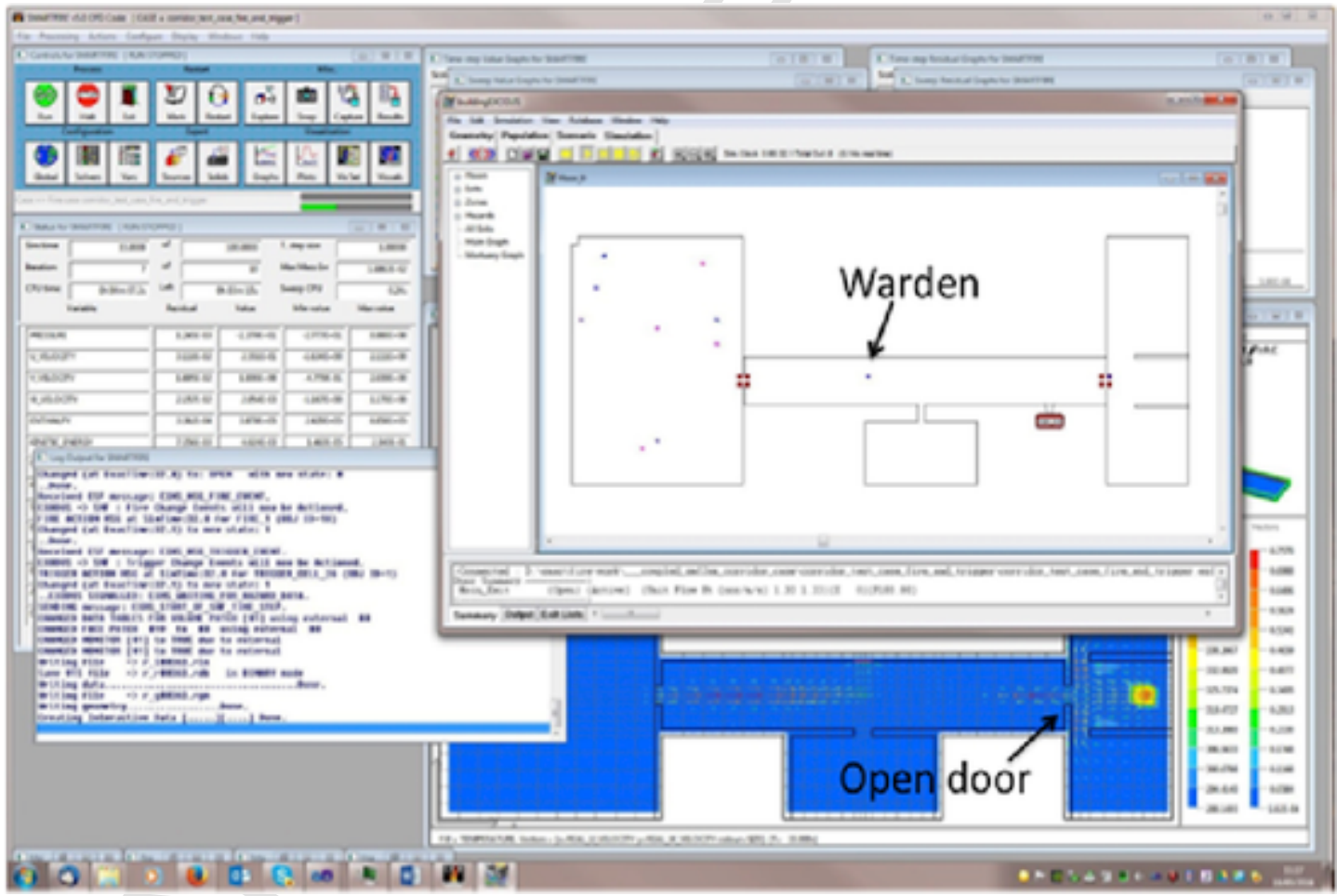

Fig. 7. SMF and mEX coupling showing the fire flow (in SMF) when the door is opened due to movement of personnel (in $\mathrm{mEX}$ ).

Fig. 7, the Warden, following the search path presented in Fig. 5, entered the cabin on the right then exited with the person positioned in the cabin. They leave open the door linking the cabin and the corridor. The open passageway creates airflow that affects the fire, as indicated by the vectors. The simulation concludes when all occupants have evacuated the structure. Since the $m E X$ and $S M F$ simulations are coupled, any doors that the Warden opens or closes will be communicated to the CFD Engine and reflected in the simulation. This means opening the fire compartment door will result in the spill of hot fire gases and smoke into the common corridor, whilst closing a door will cut off any further spread through that door. The test case simulation demonstrates the coupling of SMF and $m E X$ (including actions of opening/closing a door, which changes ventilation flow to the fire, while also allowing the escape of fire effluents into the corridor), and that actionable behaviour in the presence of an event is performed appropriately (Woolley et al., 2016). The next stage of development is to demonstrate the same coupling, and more advanced behaviours, within a simulated naval platform environment. 


\section{Use case}

The initial use case scenario for NavDIRecT will utilise the ex-HMAS Derwent geometry, a three-dimensional render of which is shown in Fig. 8. The ex-HMAS Derwent was a Royal Australian Navy (RAN) River Class Destroyer Escort (modified from the Royal Navy Type 12M Rothesay Class frigate) and decommissioned in 1994. During 1994, ex-HMAS Derwent was utilised in the SSEP and subjected to a series of live fire and explosion trials (Howe, 1996), and one of those trials will be utilised to define and validate the use case.

\subsection{Fire modelling}

Fig. 9 presents the setup details for a fire scenario in ex-HMAS Derwent. In Fig. 9 the initial location for the fire scenario is shown, with the fire commencing in the forward crew quarters on Deck 3. Fig. 9 is orientated such that, ex-HMAS Derwent's stern is towards the upper portion of the image, bow is the lower portion of the image, port is to the right and starboard to the left. In this scenario, as with the live fire trial, the ventilation conditions were: a) a hole in the starboard hull of the Deck 3 representing damage from the incoming ordinance; b) an opening (to air) in the port hull of Deck 3 representing the ordinance blast damage that initiated the fire; and c) an open hatch leading up to the corridor of Deck 2. Though shown in the open position in Fig. 9, cabin doors were closed during the fire simulation. The exceptions were the doors at either end of the corridor on Deck 2 , which, for simulation purposes, were open to outside air. The fire scenario had multiple distributed fuel packages within the crew quarters, including triple bunk mattresses. The fuel packages in the simu- lation were equivalent to the burnable items identified during a fuel survey performed prior to the SSEP fire trial, and identified in photographs showing the interior of the crew quarters of the ex-HMAS Derwent also prior to the SSEP fire trial. Fuel mass loss rates for the mattress were determined by calorimeter experiment for the free burning of a single small polyurethane foam mattress (adapted from (Vulcan Initiative, 2018)). This fuel arrangement is depicted Fig. 10 and the fuel mass loss rate curve for the mattress is shown in Fig. 11. The total amount of fuel released is equivalent to (approximately) $34 \mathrm{MW}$.

Fig. 12 presents the initial fire simulation test results (in plan view, and as cut planes of temperature at $200 \mathrm{~s}$ after the fire started), where heat transfer through the open hatch to Deck 2 can be seen immediately aft of the circular main gun bay. Fig. 12 shows the simulated results at $200 \mathrm{~s}$ into the fire, both as horizontal cut planes of temperature at head height on each deck and as vertical cut planes through the hatch between the two decks. The labels V1, V2 and V3 represent temperature measurement locations (shown in Fig. 13, described later in this paragraph). The open hatch located in the deckhead (that is, the ceiling) of Deck 3 (also being the deck (that is, the floor) of Deck 2) is, essentially, an open horizontal vent of given dimensions in the deckhead of the fire compartment. In this scenario, the temperature curves $\left({ }^{0} \mathrm{C}\right)$ measured at the open hatch to Deck 2 (located 0m above the deck) and at three points along the starboard hull where the missile entered the ship on Deck 3 are presented in the graph of Fig. 13. The three starboard points Starboard Forward Vents, Starboard Middle Vent and Starboard Aft Vent correspond, respectively, to V1, V2 and V3 labelled in Fig. 12. The graph indicates an initial spike in temperature soon after the multiple fires are initiated. At first, the hatch (acting as an open deckhead vent) has an almost identical rate of temperature rise to the other damage openings, but it appears that the rapid and (initially) increasing release
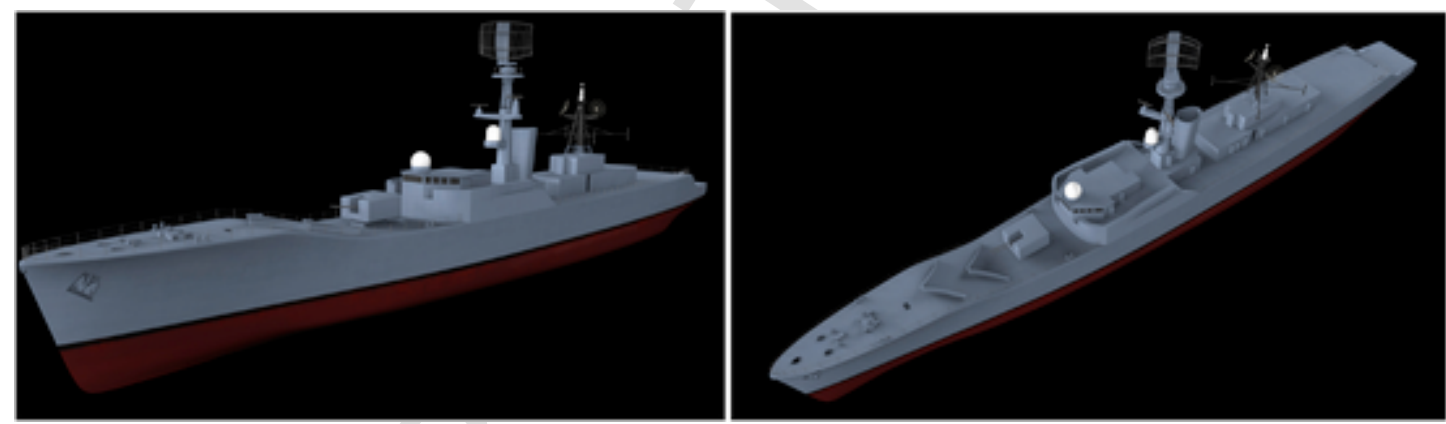

Fig. 8. Three-dimensional render of ex-HMAS Derwent.

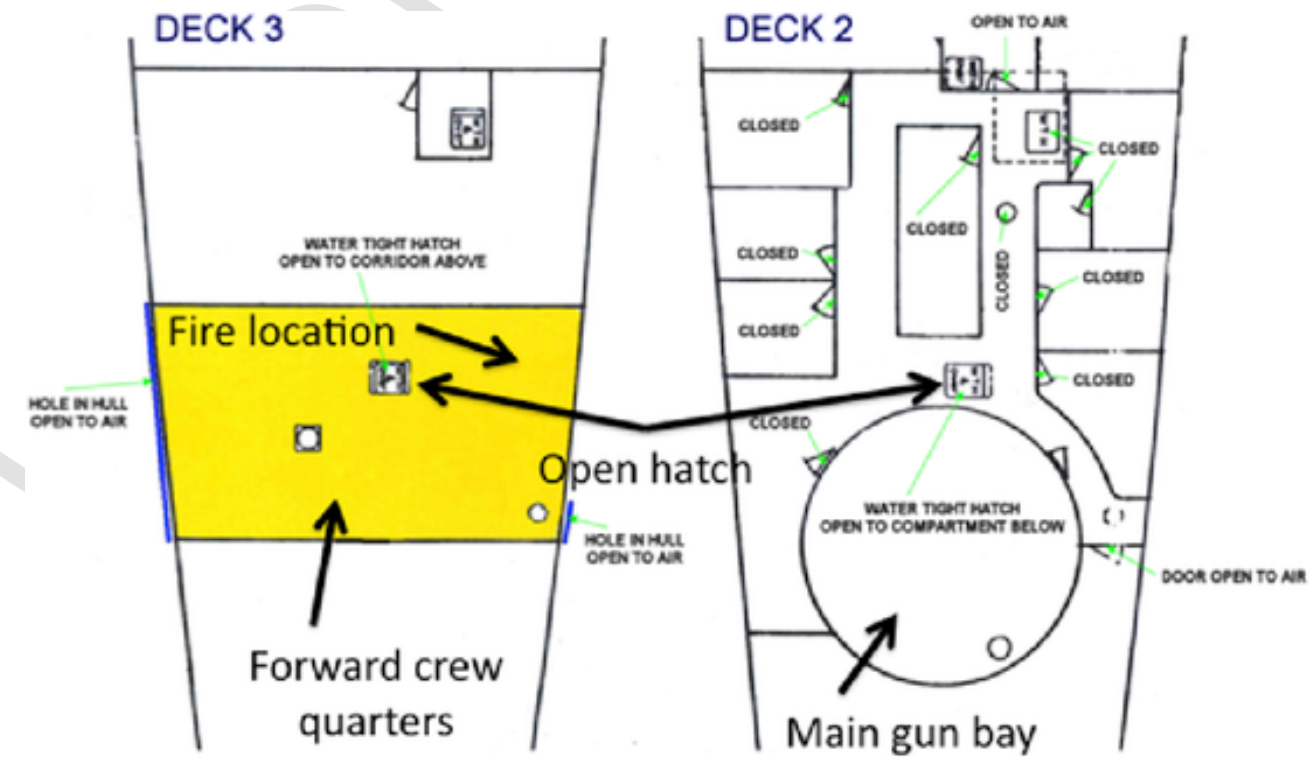

Fig. 9. ex-HMAS Derwent fire scenario configuration. 


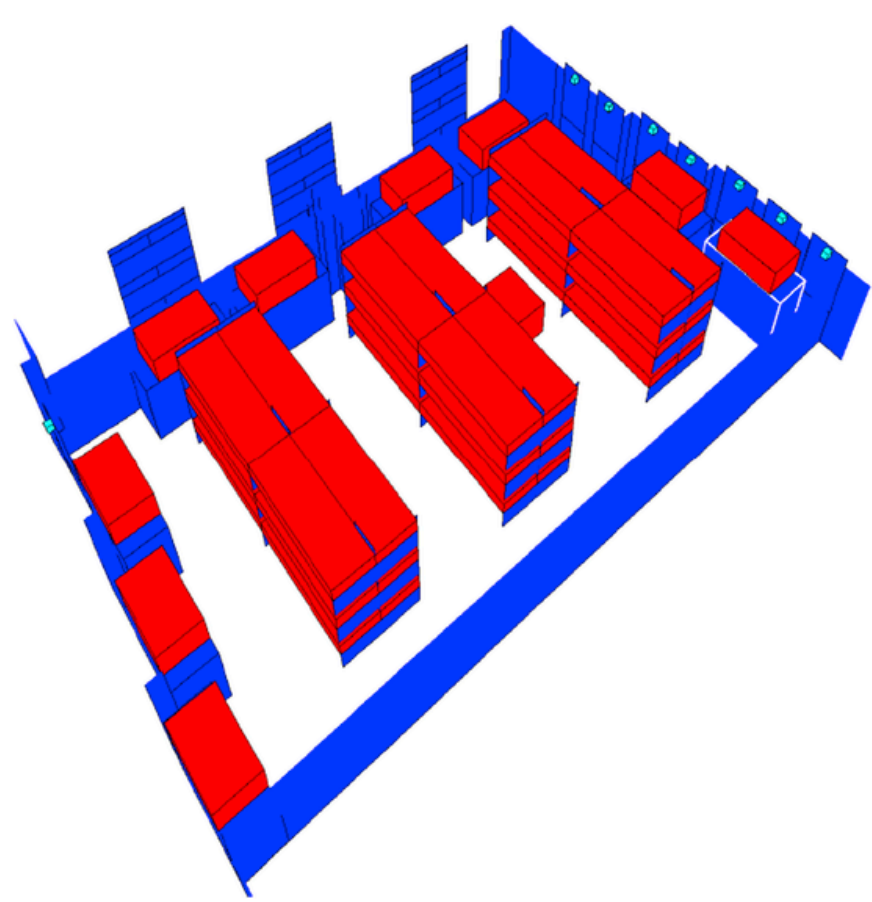

Fig. 10. Distribution of fuel packages in the forward crew quarters (triple bunk mattresses and drawer units). The starboard hull has the window-like openings (representing the missile entry point) in the upper diagonal left; forward is the lower diagonal left.

of heat from all the beds and furniture means that the dimensions of the hatch are insufficient to allow all the hot gases to vent through the hatch. Consequently, hot fire gases proceed to spill out of the damaged areas of the hull, mostly in the middle opening of the starboard hull. As the individual fires pass their peak output, the rate of fuel release starts to decrease, the hatch can, again, become a significant flow route. This results in another brief temperature spike at the hatchway. After the second spike the fuel sources are mostly consumed and the temperature through the hatch and damage openings progressively decreases. To conclusively understand the fire behaviour in this scenario, further analysis is required. This will be a topic of future research. For this scenario, the initiating blast was assumed to immediately ignite all of the distributed fuel sources. This modelling approach may be unrepresentative of the initial stages of the real fire as (a) the shockwave from blast may have relocated fuel material and furniture in the compartment; and (b) partly/ fully protected fuel material may have resulted in a slower and progressive fire spread from the initial fire location.

\subsection{Crew movement}

To demonstrate the ability of crew movement simulating naval DC SOP procedures, a simple 'blanket search' scenario was devised and applied to the ex-HMAS Derwent model. For this scenario, the fire incident in the use case (Section 9.1) was assumed to have occurred and the extent of damage yet to be established. The scenario involved the formation of a search team, consisting of four crew agents, who moved through the platform to search all compartments within a specified area. The search path is presented in Fig. 14, showing a partial view of the forward section of Deck 3. The search team arrived on Deck 3 via a ladder at ' 1 ' and commenced their search moving to the compartment at ' 2 '. Compartment ' 2 ' is searched before the team moves to search the compartment at ' 3 '. From here they moved back to the ladder at ' 1 ' and continued the search on Deck 2 . When the search on Deck 2 was complete, the search team returned to Deck 3 via the ladder at ' 4 ' and continued immediately to Deck 4 via the ladder at ' 5 '. Upon completion of the search on Deck 4, the team returned to Deck 3 via the ladder at ' 5 '. From here they moved in a clockwise di-

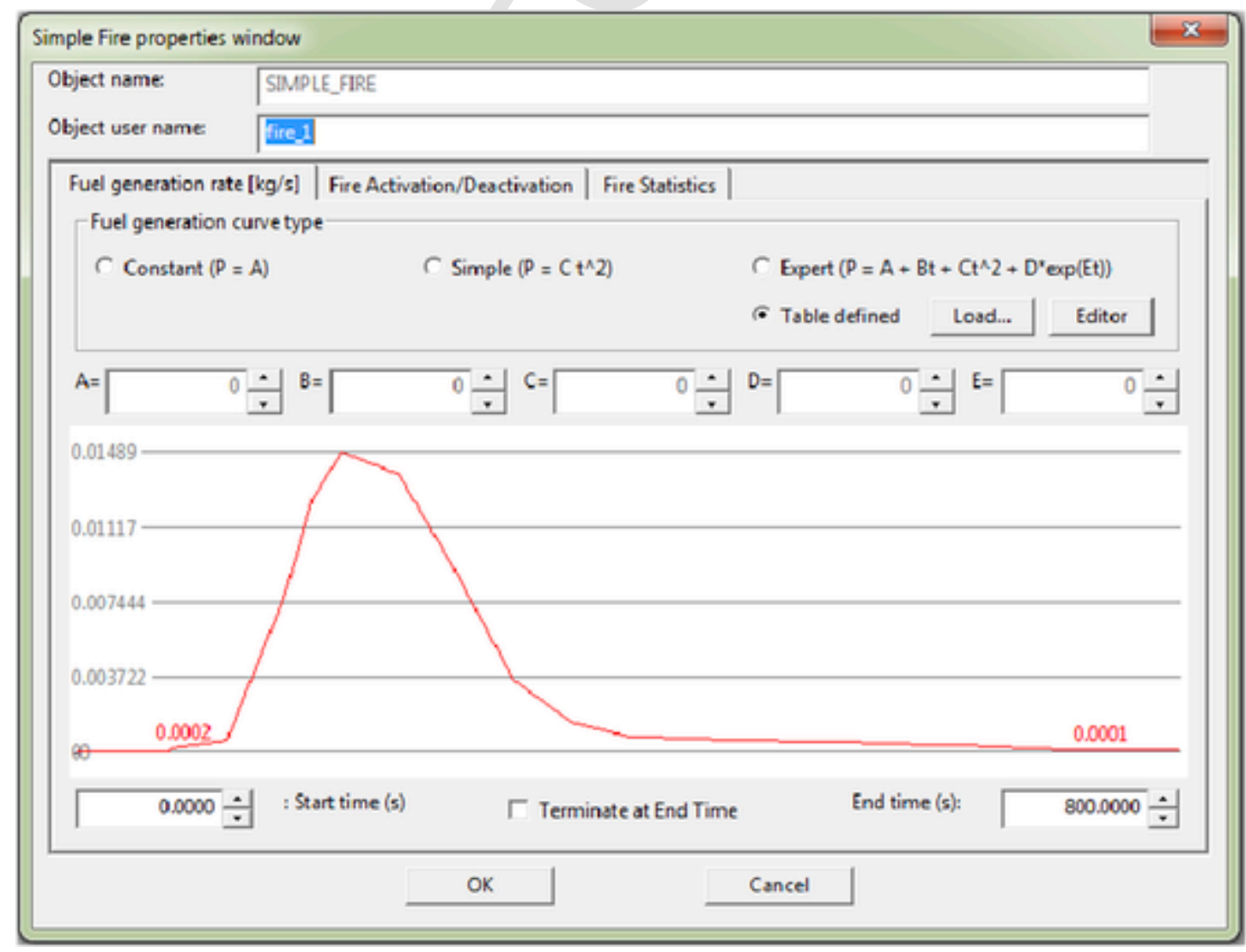

Fig. 11. Fuel packages each have a mattress with a corresponding fuel mass loss rate curve (with a peak of $745 \mathrm{~kW}$ ), adapted from (Vulcan Initiative, 2018). 


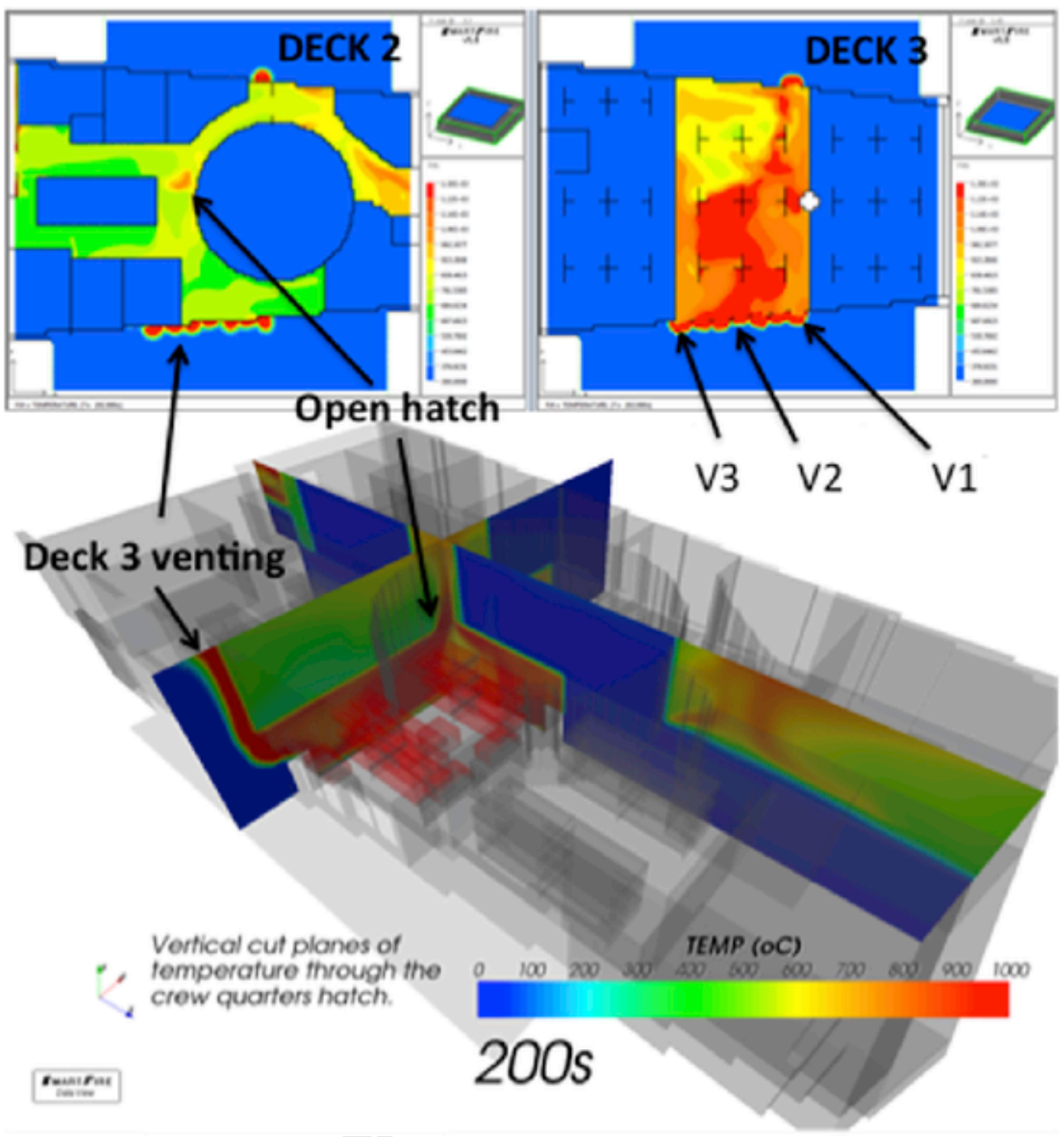

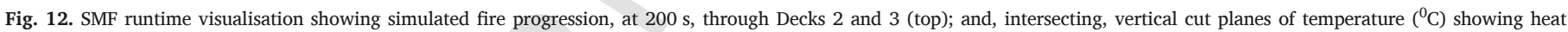
transfer between decks (bottom).

rection searching in sequence the compartments labelled ' 6 ', ' 7 ' and ' 8 '. After searching compartment ' 8 ', the team returned to the ladder at ' 4 ', and travelled up to Deck 2 where they continued the blanket search. For this scenario, the crew agents were programmed with an itinerary (that is, a route through the platform) they needed to follow. In this example, the itinerary was calculated by $m E X$ using simple heuristics that identified the furthest compartment to be explored within the search zone and then, in a clockwise direction, identifying the nearest compartment to that location. The heuristics iteratively identified the compartments to be explored from furthest to nearest, and then reversed the order of compartments (from nearest to furthest) as the search route for the crew to follow. Long term development of NavDIRecT will improve the 'intelligence' of the heuristics by applying rules as defined by, say, Behaviour Trees (Woolley and Liu, 2016) or other forms of cognitive modelling (for example (Hollmann, 2015),). Eventually, control of the crew agents will be managed by the Internal Decision and Action States; thereby enabling the search team to make autonomous decisions regarding their search pattern.

\section{Discussion}

The test case (Section 8) demonstrated the concept of integrating $S M F$ with $m E X$, showing the movement of people (opening and closing doors) affecting the state of the fire and spread of fire effluents. The test case, along with the ex-HMAS Derwent use case (Section 9) indicates that modelling a fire scenario with the movement of crew in accordance with SOPs, and in response to the fire, can be achieved.

The importance of this ability to model heat spread and crew movement is reflected in the need to understand the possibility of spontaneous 'cook-off' of explosive ordnance (Gamble et al., 2014). Using $m E X$, with scripted paths for crew movement, the time taken for crew to respond to the fire can be predicted. During the time taken for the crew to respond to the fire, concurrent modelling of fire spread can also be incorporated within the coupled simulation. This is an improvement over a previous method (Gamble et al., 2014) using event trees and SME opinion regarding the actions of the crew and the time taken to perform those actions. Previous use of the event trees utilised subjective information regarding the behaviour of crew, which resulted in subjective output. A M\&S capability, such as NavDIRecT, will produce qualitative re- 


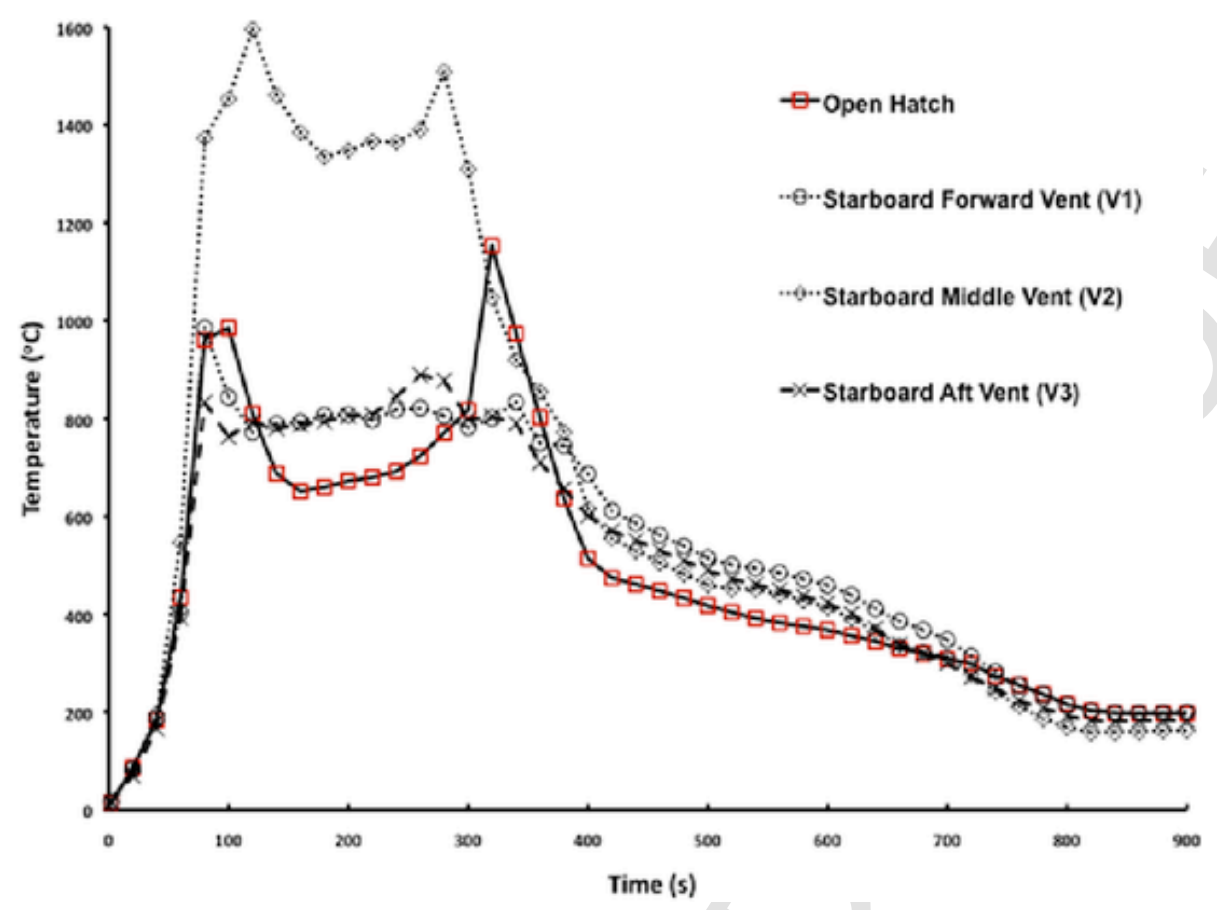

Fig. 13. Fire temperature $\left({ }^{0} \mathrm{C}\right)$ curve as measured from the open hatch and at three locations on the starboard hull.

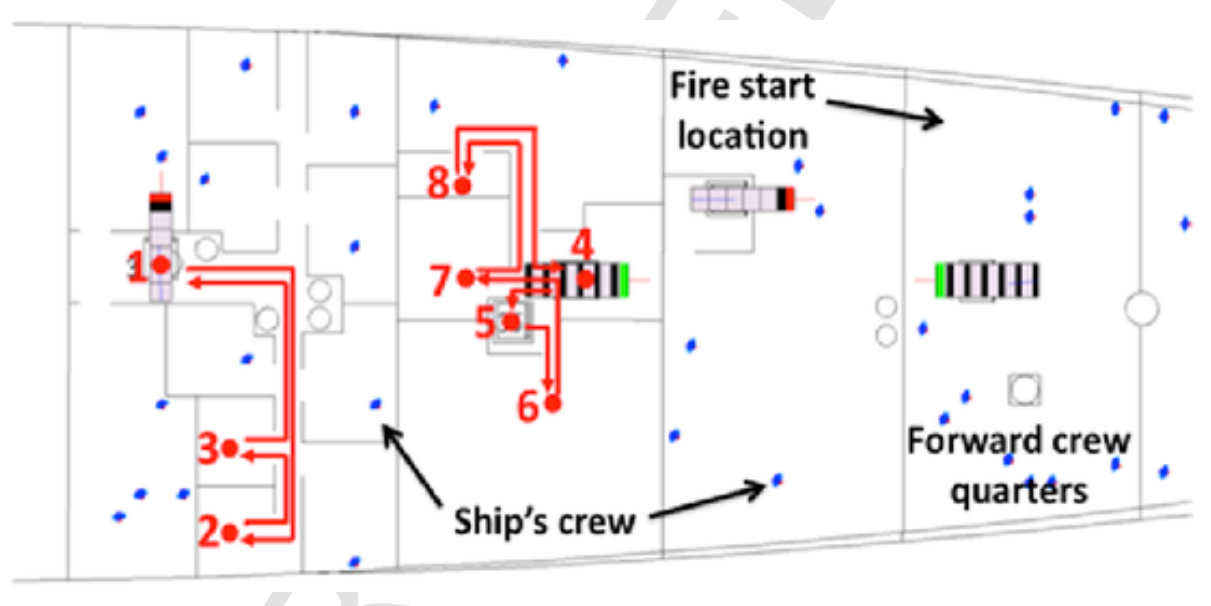

Fig. 14. Blanket search path.

sults, based on physics and mathematical understanding of the scenario, giving realistic output in which analysts have a known level of confidence based on the particular combination and fidelity of models used. The M\&S will also save time and resources when compared to developing the event trees. However, there are limitations with M\&S such as model fidelity (Section 4).

NavDIRecT modelling requirements were presented in Section 4, with some of these requirements being demonstrated in the Test Case (Section 8) and Use Case (Section 9). In particular, the requirement for modelling movement through the platform is an inherent capability of the mEX pedestrian movement tool; and the requirement to visualise simulations is inherent within $\mathrm{mEX}$ and SMF (for example, Figs. 5-7 and 12). Two other modelling requirements have also been demonstrated: crew behaviour; and temporal management. mEX, as designed, is for the analysis of escape and evacuation from structures. The Use Case (Section 9.2) demonstrated crew behaviour in the form of a 'blanket search'. During a blanket search, the crew perform a visual inspection to identify damage, the presence of fire, flood and/ or toxic hazards, and to locate incapacitated crew. Rules governing more complex behaviours (for example, fire fighting) are currently being identified using HTA (Woolley and Liu, 2016), with methods of implementation being performed under another research program (Woolley and Liu, 2016).

The second modelling requirement being demonstrated is the temporal management between SMF and mEX, as shown in the Test Case (Section 8). SMF is a CFD modelling tool, requiring time to perform a simulation run (depending on the complexity of the scenario); conversely, $\mathrm{mEX}$ can perform simulations in real time. Therefore, to enable the effects of people movement (such as the opening and closing of doors, Figs. 5-7) to be reflected in the fire modelling, temporal connectivity between the two tools needed to be established. This is achieved by computing the fire evolution for a time step within SMF, and communicating the fire hazard data to mEX. Crew are then moved within $\mathrm{mEX}$ for the next time step, with state changes (such as the opening or closing of a hatch) being communicated to SMF. The SMF model reflects those changes and models fire progression for that time step. The process is repeated until the conclusion of the simulation.

Other modelling requirements specified in Section 4 will be implemented during the development of NavDIRecT. Current considerations are being made for the database structure to store data from each of the tools, and methods to communicate database changes to the simulation tools requiring that data. 


\section{Emergent simulation capability}

During the development of the NavDIRecT capability, it is expected that new simulation capability may emerge - either by necessity, or as a result of circumstance. One example that has thus far been realised is new simulation capability developed in support of modelling the effects of fire effluents on crew. Throughout the evolution of a fire, a number of fire hazard effluents (such as, gaseous toxic species, oxygen depletion and heat) are generated. For the crew, these fire hazards can result in impaired vision movement, incapacitation or death. In the standard method of communicating $S M F$ data to $m E X$, the fire hazard data is averaged over two vertical spatial zones. One spatial zone represents the hazard level at a nominal 'head height', simulating the hazard to which a standing member would be exposed. The second spatial zone represents the hazard level at a nominal 'knee height', simulating the hazard to which a crawling crew member would be exposed. These two spatial zones are depicted on the left in Fig. 15. During $S M F-m E X$ integration for NavDIRecT, two new methods of fire effluent sharing were developed. In the first, the zonal representation of the hazard data was increased to have at least 10 continuous regions in height, instead of just two disparate zones. This results in greater spatial accuracy for the perception of fire hazards in the height direction. This multi-zone representation of hazard data is also depicted in Fig. 15. The development of this capability enables rendering of the fire and smoke simulation within Unity for visualising the effects of smoke (such as, obscuration by soot particles thereby reducing visibility) and temperature (for example, simulating the use of thermal imaging cameras).

Another emergent hazard modelling capability was a 'Points-of-Interest' (PoI) hazard formulation. This enables the local hazard environment to be focussed to a single point, such as in the vicinity around a person's head in regions with high gradients of hazard properties (for example, near strong ventilation flows, or nearing proximity to fires). The PoI toxic hazard formulation can be used to model the effect of fire effluents on individual crew trying to evacuate a space affected by fire or, in the longer-term, other toxic atmospheres - such as chemical warfare agents. Consider, for example, the analysis of the fire on board HMAS Westralia in 1998 (Kennett et al., 1998). The analysis showed carbon monoxide concentration throughout the compartment; however, the fire modelling capability at the time of the analysis could only be used to estimate the effects on the crew. The new PoI hazard formulation can now be utilised to model the toxicity concentration levels to which each person would be exposed as they move through the platform. The new PoI hazard formulation does not contain averaged hazard information (as would have been previously the case in the standard method of communicating $S M F$ fire data to $m E X$ ). Consequently, this emergent capability will enable analysis of the crew during fire-fighting and recoverability operations. Additionally, during crew training, the capability will allow the platform crew to familiarise themselves with the perceivable and non-perceivable effects of fire and to understand the toxicity of fire effluents.

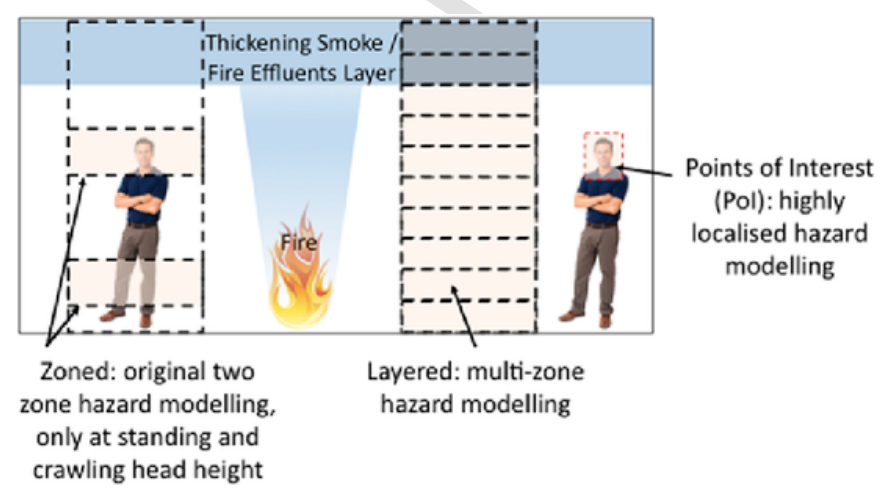

Fig. 15. New, enabling fire and fire effluents modelling capability.

\section{Relevance to merchant and commercial shipping}

NavDIRecT, while designed for the needs of naval recoverability, also has application in merchant and commercial shipping. The NavDI$\operatorname{Rec} T$ framework can easily be adapted to any maritime platform, and a wide range of scenarios. It is only the underlying data and models (such as models relating to SOPs) that are specific to naval, merchant and commercial platforms. A comparison of the application of naval survivability assessment for use in merchant and commercial shipping in civilian and multi-mission scenarios examined the differences in requirement between naval and merchant platforms (Papanikolaou and Boulougouris, 2000; Nate and Goodfriend, 2015). Relevant to merchant and commercial shipping are the requirements defined in the International Convention for the 'Safety of Life at Sea' (SOLAS) (IMO, 2014). Therefore, analysis of merchant and commercial shipping only requires relevant platform models to be developed, and an understanding of crew SOPs to define the necessary crew movement and behaviour in $m E X$. The techniques being applied for the analysis of naval crew behaviour (Liu and Woolley, 2015; Liu and Woolley, 2016) are also applicable for analysing merchant crew behaviour, with the anticipated method of implementation also being suitable for modelling merchant and commercial crew. Subsequently, NavDIRecT will enable analysis and validation of platform design in accordance with SOLAS (IMO, 2014).

\section{Future work}

The development of NavDIRecT, with the integration of SMF and $m E X$, has the potential for being used in delivery of future recoverability analysis capability, such as:

- fire suppression and/or extinction;

- boundary cooling to control the spread of the fire and heat to prevent secondary events (such as explosive ordnance cook-off);

- multiple incidents and evolving incident analysis;

- blanket search for the discovery, and rescue, of injured crew, and identification of fire and toxic hazards; and

- crew perception and reporting of the fire environment by identifying smoke and heat.

To assist in delivery of the future capability, a number of key research areas will be explored. This includes modelling realistic decision-making and response actions of the crew; visualising and communicating DC simulations and output; and verifying and validating the NavDIRecT framework. Expanding NavDIRecT capability to analyse other forms of damage incidents such as flooding using, for example, FREDYN (Ypma and Turner, 2019), will also be examined.

\subsection{Crew skill}

During incident response, the effectiveness of crew performing recoverability SOPs is governed by their level of skill, knowledge and experience. Naval recoverability and DC training is an intense and ongoing process. The training also includes focus on performing SOPs within specific time frames. Exceed those time frames and the risk of mission failure, loss of life and loss of ship increases. There is also the possibility of crew not performing, or incorrectly performing, specific tasks dictated by the SOPs. This is likely to arise due to lack of experience, or might occur under the stress and fatigue created during the incident response. Therefore, ability to model crew skill, proportional to experience or fatigue, will be a future requirement. Furthermore, understanding how individual skills contribute to team behaviour and effectiveness will be necessary when modelling firefighting activities and how those activities affect the fire. Modelling crew performing SOPs using 'behaviour trees' is currently one option being explored (Woolley and Liu, 2016); however, at this stage, this solution only models the activity itself and not the skill with which the activity 
is being performed. Ability to model crew ability to perform SOPs, such as speed and efficiency will facilitate analysis of crew training, and of the SOPs. When crew models are developed, changes to crew skill and SOPs will be serviced by the NavDIRecT databases and plug-and-play functionality.

\subsection{Virtual Reality and Augmented Reality}

The functionality provided by the game engine enables the use of VR and AR technology. This will allow for 'human-in-the-loop' engagement within DC simulations and allow users to affect the outcome of a simulation (Narayanan and Kidambi, 2011). Such a capability may be utilised, for example, to enhance damage control training. In the VR and AR environments, crew might interact with other crew undergoing training, and also with computer controlled agents, to familiarise themselves with platform configuration; to simulate extreme scenarios that cannot be achieved via other forms of training; and to explore the application safety systems and SOPs. With the ongoing development of NavDIRecT, the training and development capability, suitable for use within naval, and merchant and commercial shipping environments, will progress as emergent, enabling technology.

The use of VR and AR will also facilitate the communication of results to suit stake-holder decision-making processes. Utilising VR and $\mathrm{AR}$, the results from any analysis may be mapped to a real-world context, giving clarity to the analysis process. This will also assist with communicating results to clients who may not have requisite expertise to interpret the meaning conveyed by the analysis. VR and AR will, therefore, enable stakeholders to view and optimise design changes, and make informed decisions. Some of this capability has already been demonstrated by the European Union (EU) Horizon 2020 project, AUGGMED (FSEG, $2018 \mathrm{~b}$ ), where the buildingEXODUS and SMF software were coupled to the Unity simulation environment to develop a VR/AR training environment for first responders reacting to terrorist scenarios within crowded environments.

\subsection{Verification and validation of NavDIRecT}

Some comparative studies of individual software tools (for example, $S M F$ and $m E X$ ) has occurred to determine the accuracy of the models within the tools (Grech et al., 2012; Gamble et al., 2014); and validation studies of $m e X$ and SMF have occurred (Galea et al., 2013, 2017). However, V\&V of the integrated software environment will need to be performed (whether for naval platforms or merchant shipping). When complete, this will give confidence in the analysis, and an ability to quantify the variance and estimated level of errors in the results.

\section{Conclusion}

The output from the current phase of NavDIRecT development has successfully delivered a coupled fire and crew movement modelling capability. A proof of concept test case, integrating fire simulation and crew movement behaviour, has also been demonstrated. Realistic fire and crew behaviour has also been demonstrated, using mathematical models to simulate interacting fire and crew behaviour. The integration of $S M F$ and $m E X$ has enabled the development of a integrated framework to analyse naval platform recoverability. When fully developed, NavDI$\operatorname{Rec} T$ will be a significant improvement over other analysis techniques that use static assessment of the probability of kill, or event trees with subjective data.

The development approach, using a game engine at the core of the simulation framework, provides numerous, significant benefits over existing implementations to model of Integrated Survivability. The game engine allows for modular changes and scalability of the framework as suitable (or more suitable) M\&S capabilities become available, or new threats and recoverability capabilities and procedures are developed. The game engine will also facilitate future ideas for VR and AR scenarios and training utilising the NavDIRecT framework. This will enhance damage control training, allowing crew to familiarise themselves with platform configuration, and safety systems and procedures. VR and AR will also enable platform design trade-off analysis.

The outcome from NavDIRecT development will facilitate assessment of naval platforms to ensure they conform to survivability requirements. NavDIRecT will enable platform design assessment during acquisition and through-life upgrade, giving designers and mission planners the ability to assure platform capability against specification requirements.

\section{Uncited references}

Apache Software Foundation, 2016.

\section{CRediT authorship contribution statement}

Anthony Woolley: Conceptualization, Methodology, Investigation, Writing - original draft, Writing - review \& editing, Project administration. John Ewer: Conceptualization, Methodology, Software, Investigation, Writing - original draft, Visualization, Supervision, Project administration. Peter Lawrence: Conceptualization, Methodology, Software, Writing - original draft, Supervision, Project administration. Steven Deere: Conceptualization, Methodology, Software, Investigation, Writing - original draft, Visualization. Anthony Travers: Conceptualization, Methodology, Software, Writing - original draft. Tom Whitehouse: Conceptualization, Methodology, Investigation, Writing - original draft, Supervision. Edwin Richard Galea: Conceptualization, Supervision, Funding acquisition.

\section{Declaration of competing interest}

The authors declare the following financial interests/personal relationships which may be considered as potential competing interests: Research performed by Fire Safety Engineering Group (FSEG), University of Greenwich, was supported by DST Group under Research Agreement 5460 between DST Group and University of Greenwich.

DST Group and TNE Solutions, developers of Integrated Recoverability Model (IRM) as documented herein, have an agreement to co-develop recoverability scenarios using IRM.

DST Group did not receive any grant from funding agencies in the public, commercial or not-for-profit sectors.

\section{Acknowledgements}

The authors acknowledge Director Naval Technical Bureau, RAN, as sponsor of this work. NavDIRecT is a combined effort with contributions from numerous specialists. The authors thank the following staff from Defence Science and Technology Group: Marcus Saunders for assistance during ISSAC requirements analysis; Vanessa Pickerd and Pat McCarthy (retired) for vulnerability advice; Serap Aksu for systems analysis advice; Grant Gamble, Ian Burch and Brigitta Suendermann for fire and smoke modelling and platform recoverability advice; and Jenny Liu and Warren Roberts for human behaviour analysis advice. Finally, the authors also thank Guido Papp, QinetiQ Australia, and Noel Richards, Deakin University for development of the ex-HMAS Derwent model.

\section{References}

T\&E Integrated recoverability model (IRM). Test and evaluation solutionshttp://www.irmsoftware.org/2019accessed 15 November 2019

Amazon Amazon DynamoDBhttps://aws.amazon.com/dynamodb/2019accessed 15 November 2019

Apache Software Foundation Cassandrahttps://cassandra.apache.org/2016accessed 15 November 2019

Azzi, C, Pennycott, A, Mermiris, G, Vassalos, D, 2011. Evacuation simulation of shipboard fire scenarios. In: Fire and Evacuation Modeling Technical Conference Proceedings 15 - 16 August 2011, Baltimore, Australia.

Ball, R E, Calvano, C N, 1994. Establishing the fundamentals of surface ship survivability design discipline. Nav. Eng. J. 106, 71-74. doi:10.1111/j.1559-3584.1994.tb02798.x.

Birta, L G, Arbez, G, 2007. Modelling and Simulation: Exploring Dynamic System Behaviour [electronic Resource]. Springer, London. 
Boulougouris, E, Papanikolaou, A, 2004. Optimisation of the survivability of naval ships by genetic algorithms. In: Third International Conference on Computer Applications and Information Technologies in the Maritime Industries Proceedings 9 - 12 May 2004, Siguenza, Spain.

Boulougouris, E, Papanikolaou, A, 2013. Risk-based design of naval combatants. Ocean Eng. 65, 49-61.

Brett, J, Gamble, G, Reid, W, Smith, S, Woolley, A, Yiannakopoulos, G, 2017. Integrated survivability analysis of naval platforms in high threat environments. In: Pacific 2017 International Maritime Conference Proceedings 3 - 5 October 2017, Sydney, Australia.

Buckland, M, 2008. The use of warship vulnerability analysis tools as a measurement of blast and ballistic protection requirements. In: Pacific 2008 International Maritime Conference Proceedings 29-31 January 2008, Sydney, Australia.

Burd, G, 2011. NoSQL. ;login. The Usenix Magazine 36 (5).

Burnett, E, 2008. A proposed model fidelity scale. In: AIAA Modelling and Simulation Technologies Conference and Exhibit 18 - 21 August 2008, Honolulu, USA.

Commonwealth of Australia, 1998. Report of the Board of Inquiry into the Fire in HMAS Westralia on 5 May 1998 Volume 1. DPUBS: 32871/98. Department of Defence, Australia.

Cramp, A, 2009. Simulating Multiple Systems of Systems Using the High Level Architecture. PhD Thesis, University of Adelaide, Australia.

de Yong, L, 2008. Integrated ship survivability for the royal Australian Navy. In: Pacific 2008 International Maritime Conference Proceedings. pp. 29-31 January 2008, Sydney, Australia.

Deere, S J, Galea, E R, Lawrence, P, 2008. In: Bertram, V, Rigo, R (Eds.), Assessing Naval Ship Design for Human Factors Issues Associated with Evacuation and Normal Operations. COMPIT08. In: 21-23 April 2008 Liege Belgium. pp. 33-47 -10 2-9600785-0-0.

Department of Defense, 2016. Modelling and Simulation (M\&S) Glossary - Terms \& Definitions E-H. Modelling and Simulation Coordination Office. Department of Defense, United States of America. https://www.msco.mil/MSReferences/Glossary/ TermsDefinitionsE-H.aspx accessed 15 November 2019.

R.A.D.M.F. Drennan Command Investigation into the fire that occurred onboard USS George Washington (CVN 73) on 22 MAY 2008http://www.cpf.navy.mil/content/ foia/washington/FOIA_GW_Fire_investigation.pdf2008accessed 15 November 2019

Ewer, J, Jia, F, Grandison, A, Frost, I, Galea, E, Patel, M, 2013. Technical Reference Manual and User Guide for SMARTFIRE 4.3. University of Greenwich, UK.

Floyd, J, Hunt, S, Williams, F, Tatem, P, 2005. A network fire model for the simulation of fire growth and smoke spread in multiple compartments with complex ventilation. J. Fire Protect. Eng. 15, 199-229.

FSEG maritimeEXODUS/SMARTFIRE coupling demo videohttps://www.youtube.com/ watch?v = dNIQWcn0MlE2018accessed 15 November 2019

FSEG AUGGMED. European union Horizon 202 research and innovation programme, grant agreement number 653590https://fseg.gre.ac.uk/fire/auggmed.html2018accessed 15 November 2019

FSEG, 2019. EXODUS. Fire Safety Engineering Group. The Faculty of Architecture, Computing \& Humanities, University of Greenwich. http://fseg.gre.ac.uk/exodus accessed 15 November 2019.

Galea, E R, Lawrence, P, Gwynne, S, Sharp, G, Hurst, N, Wang, Z, Ewer, J, 2004. Integrated fire and evacuation in maritime environments. In: Proceedings of the 2nd International Maritime Safety Conference on Design for Safety. Sakai Japan, Publisher Ship and Ocean Foundation, pp. 161-170 27 - 30 Oct 2004.

Galea, E R, Deere, S, Brown, R, Filippidis, L, 2013. An experimental validation of an evacuation model using data sets generated from two large passenger ships. J. Ship Res. 57 (3), 155-170.

Galea, E R, Lawrence, P J, Filippidis, L, Blackshields, D, Cooney, D, Sharp, G, 2016. maritimeEXODUS v5.1 Theory Manual, Revision 1.1. University of Greenwich, UK.

Galea, E R, Wang, Z, Jia, F, Lawrence, P J, Ewer, J, 2016. Fire safety assessment of Open Wide Gangway underground trains in tunnels using coupled fire and evacuation simulation. Fire Mater. 41 (6), 716-737. doi:10.1002/fam.2413.

Galea, E R, Wang, Z, Jia, F, 2017. Numerical investigation of the fatal 1985 Manchester airport B737 fire. Aeronaut. J. 121 (1237), 287-319. doi:10.1017/aer.2016.122.

Gamble, G, Suendermann, B, Mathys, Z, Woolley, A, 2014. Fire modelling and event tree analysis for naval platform fire incidents. In: International Conference on Fire at Sea Proceedings. pp. 26-27 March 2014, London, UK.

Grech, M, Drohan, D, Roberts, W, Gamble, G, 2012. Ship recoverability: how important is the human factors input? In: Pacific 2012 International Maritime Conference Proceedings, 30 January - 2 February 2012 (Sydney, Australia).

Hollmann, C, 2015. A Cognitive Human Behaviour Model for Pedestrian Behaviour Simulation. PhD Thesis, University of Greenwich, UK.

Howe, J, 1996. Ship Survivability Enhancement Program: Management of the Program. DSTO-GD-0087. Defence Science and Technology Organisation, Australia.

IMO, 2014. International Convention for the Safety of Life at Sea. International Maritime Organization.

Kabir, S, 2017. An overview of fault tree analysis and its application in model based dependability analysis. Expert Syst. Appl. 77, 114-135. doi:10.1016/ j.eswa.2017.01.058.

Kennett, S, Gamble, G, Li, J-D, 1998. Modelling of the HMAS Westralia Fire. DSTO-TR-0698, Defence Science and Technology Organisation, Australia.

Kok, S, 2012. Naval Survivability and Susceptibility Reduction Study - Surface Ship. Naval Postgraduate School, USA Masters Thesis.

Liu, J, Woolley, A, 2015. Holistic analysis of crew cognition and interaction during naval damage control. In: International Conference Damaged Ship III Proceedings. pp. 25-26 March 2015, London, UK.
Liwang, H, Jonsson, H, 2015. Comparison between different survivability measures on a generic frigate. Trans. of the R. Inst. of Nav. Archit Part A2: Int. J. of Marit. Eng. 157, A125-A134.

McGrattan, K, Hostikka, S, McDermott, R, Floyd, J, Weinschenk, C, Overholt, K, 2016. Fire Dynamics Simulator User's Guide. sixth ed. NIST Special Publication 1019 FDS Version 6.5.2, Revision: Git-r23-0-g4e9103f, USA. doi:10.6028/NIST.SP.1019.

Ministry of Defence, 1982. Loss of HMS Sheffield - Board of Inquiry. Ministry of Defence, UK. http://clashofarms.com/files/BOI_Rpt_HMS_Sheffield_May82.pdf accessed 15 November 2019.

Narayanan, S, Kidambi, P, 2011. Interactive simulation: history, features, and trends In: Rothrock, L, Narayanan, S (Eds.), Human-in-the-Loop Simulations - Method and Practice. Springer-Verlag, London, pp. 1-13.

Nate, M, Goodfriend, B, 2015. Application of modeling and simulation methodologies to enhance non-combatant naval survivability. In: World Maritime Technology Conference Proceedings. Rhode Island, USA, pp. 3-7 November 2015.

Papanikolaou, A, Boulougouris, E, 2000. Design aspects of survivability of surface naval and merchant ships. In: Dracos Vassalos, V, Hamamoto, M, Papanikolaou, A, Molyneux, D (Eds.), Contemporary Ideas on Ship Stability, 1st ed. pp. 553-564. doi:10.1016/B978-008043652-4/50043-2.

Peniston, B, 2013. No Higher Honor: Saving the USS Samuel B. Roberts in the Persian Gulf. Naval Institute Press 1591146763.

Piperakis, A S, Andrews, D J, 2014. A comprehensive approach to survivability assessment in naval ship concept designs. Trans of the RINA Part A4. Int.. J. Maritime Eng. 156, 333-352.

Reid, M, 2000. An evaluation of the high level architecture (HLA) as a framework for NASA modelling and simulation. In: $25^{\text {th }}$ NASA Software Engineering Workshop Proceedings, 30 November 2000, Maryland, USA.

Robinson, K, Tramoundanis, D, Harvey, D, Jones, C A P T M, Wilson, S, 2010. Demonstrating Model-Based Systems Engineering for Specifying Complex Capability. Syst. Eng./Test \& Eval. Conf., Adelaide, Australia 3 - 6 May 2010.

Sajdak, J A W, Karni, Z H, 2006. Determination of a measure of total integrated system survivability. In: Warship 2006 - Future Surface Warships International Conference Proceedings 20 - 21 June 2006, London, UK.

Sauter, M, 2015. GPGPU Enabled CFD Simulation for Fully Coupled Fire and Evacuation Modelling. University of Greenwich PhD thesis. http://gala.gre.ac.uk/18139 accessed 15 November 2019.

Schofield, J, 2009. SURVIVE and SURVIVE Lite - Survivability Assessment from Concept to Operational Support. QINETIQ/09/00063. QinetiQ Ltd, UK.

Sims, B, 2012. Approaches to Open Technology Systems Specification. DSTO-TN-1087, Defence Science and Technology Organisation, Australia.

Söbke, H, Streicher, A, 2016. Serious games architectures and engines. In: Dörner, R, Göbel, S, Kickmeier-Rust, M, Masuch, M, Zweig, K (Eds.), Entertainment Computing and Serious Games: International GI-Dagstuhl Seminar 15283, Dagstuhl Castle, Germany, July 5-10, 2015, Revised Selected Papers. Springer International Publishing, pp. 148-173 https://doi.org//10.1007/978-3-319-46152-6_7.

Söderbäck, K, 2017. Design, Implementation, and Performance Evaluation of HLA in Unity. Dissertation, Linköping University. http://urn.kb.se/resolve?urn = urn:nbn:se: liu:diva-138127 accessed 15 November 2019.

SURMA Surma - survivability manager applicationhttp://survivability.fi/combat php2019accessed 15 November 2019

Turner, S D, Horstmann, P, Bain, G, 2006. Warship survivability. QentiQ. Document identifier: QINETIQ/D\&TS/SEA/JP0606887. In: Warship 2006 - Future Surface Warships International Conference Proceedings, 20 - 21 June 2006 (London, UK).

Unity https://unity3d.com/2019accessed 15 November 2019

Vasudevamurt, V, Uskov, A, 2015. Serious game engines: analysis and applications. In: IEEE International Conference on Electro/Information Technology (EIT) Proceedings. IEEE, pp. 440-445 21 - 23 May 2015. doi:10.1109/EIT.2015.7293381.

Vulcan Initiative Fuel packages for 3-D simulationshttp://www.vulcan-initiative.net/ impactfuel.html2018accessed 15 November 2019

Wang, Z, Jia, F, Galea, E, Ewer, J, 2013. A CFD simulation of a post-crash aircraft fire test. J. Aircraft 50 (1), 164-175.

Woolley, A, Gould, M I D N R, 2015. An integrated capability to assess RAN platform recoverability after a damage event. In: Pacific 2015 International Maritime Conference Proceedings 6 - 8 October 2015, Sydney, Australia.

Woolley, A, Liu, J, 2016. Cognitive modelling of crew response during naval damage control operations. In: International Conference on Human Factors in Ship Design and Operation 28 - 29 September 2016, London, UK.

Woolley, A, Ewer, J, Lawrence, P, Travers, A, Deere, S, Whitehouse, T, Galea, E, 2016. A modelling and simulation framework to assess naval platform integrated survivability. In: MAST Europe 2016 Proceedings 21 - 23 June 2016, Amsterdam, Netherlands. https://mastconfex.com/europe2016/.

Ypma, E L, Turner, T, 2019. An approach to the validation of ship flooding simulation models. In: Belenky, V, Spyrou, K, van Walree, F, Almeida Santos Neves, M, Umeda, N (Eds.), Contemp. Ideas on Ship Stabil. Fluid Mech. And its Appl., 119. Springer, Cham, pp. 637-675. doi:10.1007/978-3-030-00516-0_38. 